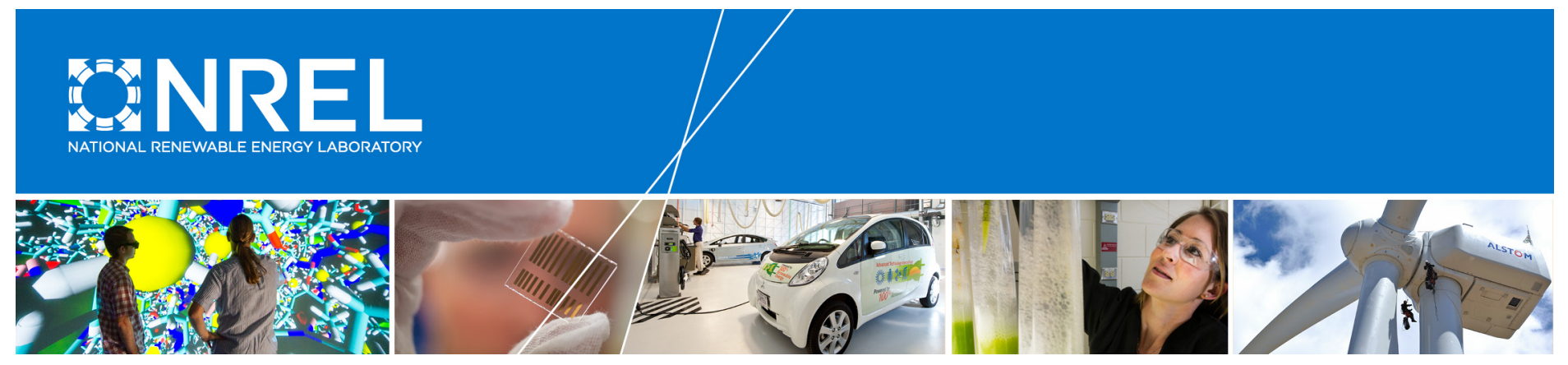

\title{
The Potential for Energy Storage to Provide Peaking Capacity in California under Increased Penetration of Solar Photovoltaics
}

Paul Denholm and Robert Margolis National Renewable Energy Laboratory

NREL is a national laboratory of the U.S. Department of Energy Office of Energy Efficiency \& Renewable Energy Operated by the Alliance for Sustainable Energy, LLC

This report is available at no cost from the National Renewable Energy Laboratory (NREL) at www.nrel.gov/publications.

Technical Report

NREL/TP-6A20-70905

March 2018 


\section{The Potential for Energy Storage to Provide Peaking Capacity in California under Increased Penetration of Solar Photovoltaics}

Paul Denholm and Robert Margolis National Renewable Energy Laboratory

Prepared under Task No. SETP.10310.11.01.14 for the U.S. Department of Energy
NREL is a national laboratory of the U.S. Department of Energy Office of Energy Efficiency \& Renewable Energy Operated by the Alliance for Sustainable Energy, LLC

This report is available at no cost from the National Renewable Energy Laboratory (NREL) at www.nrel.gov/publications.

\section{Technical Report}

NREL/TP-6A20-70905

March 2018

Contract No. DE-AC36-08GO28308
National Renewable Energy Laboratory 5013 Denver West Parkway

Golden, CO 80401

303-275-3000 • www.nrel.gov 


\title{
NOTICE
}

This report was prepared as an account of work sponsored by an agency of the United States government. Neither the United States government nor any agency thereof, nor any of their employees, makes any warranty, express or implied, or assumes any legal liability or responsibility for the accuracy, completeness, or usefulness of any information, apparatus, product, or process disclosed, or represents that its use would not infringe privately owned rights. Reference herein to any specific commercial product, process, or service by trade name, trademark, manufacturer, or otherwise does not necessarily constitute or imply its endorsement, recommendation, or favoring by the United States government or any agency thereof. The views and opinions of authors expressed herein do not necessarily state or reflect those of the United States government or any agency thereof.

This report is available at no cost from the National Renewable Energy Laboratory (NREL) at www.nrel.gov/publications.

Available electronically at SciTech Connect http:/www.osti.gov/scitech

Available for a processing fee to U.S. Department of Energy and its contractors, in paper, from:

\author{
U.S. Department of Energy \\ Office of Scientific and Technical Information \\ P.O. Box 62 \\ Oak Ridge, TN 37831-0062 \\ OSTI http://www.osti.gov \\ Phone: 865.576.8401 \\ Fax: 865.576.5728 \\ Email: reports@osti.gov
}

Available for sale to the public, in paper, from:

\author{
U.S. Department of Commerce \\ National Technical Information Service \\ 5301 Shawnee Road \\ Alexandria, VA 22312 \\ NTIS http://www.ntis.gov \\ Phone: 800.553 .6847 or 703.605 .6000 \\ Fax: 703.605.6900 \\ Email: orders@ntis.gov
}




\section{Acknowledgments}

Assistance in generating and processing solar data was provided by Bethany Frew and Janine Freeman. Josh Eichman provided the measured CAISO load and solar data. Reviews and other assistance were provided by Mihir Desu and Lon Huber (Strategen), Praveen Kathpal (Fluence), Dirk Weiss (First Solar), Aaron Bloom, Wesley Cole, Bethany Frew, Elaine Hale, Thomas Jenkin, and Dave Mooney. Editing and graphics support was provided by Mike Meshek, Devonie McCamey, and Jarrett Zuboy.

Finally, we gratefully acknowledge funding for this work from the U.S. Department of Energy's Office of Energy Efficiency and Renewable Energy under contract number DE-AC36$08 \mathrm{GO} 28308$.

\section{Disclaimer}

The views and opinions of the authors expressed herein do not necessarily state or reflect those of the United States Government or any agency thereof. Neither the United States Government nor any agency thereof, nor any of their employees, makes any warranty, expressed or implied, or assumes any legal liability or responsibility for the accuracy, completeness, or usefulness of any information, apparatus, product, or process disclosed, or represents that its use would not infringe privately owned rights. 


\section{List of Acronyms}

\section{CAISO}

CEC

CPUC

CSP

EIA

MW

MWh

NREL

PV
California Independent System Operator California Energy Commission

California Public Utilities Commission concentrating solar power

U.S. Energy Information Administration megawatt

megawatt-hour

National Renewable Energy Laboratory

solar photovoltaic 


\section{Executive Summary}

The cost of battery-based energy storage has declined dramatically in recent years, presenting an opportunity for energy storage to perform functions currently met by conventional generators that serve peak electricity demand. Peaking capacity represents a large potential market for energy storage. However, the technical and economic limits to the amount of energy storage that could be deployed as peaking capacity are poorly understood. The use of storage can change the "shape" of the peak demand period, potentially requiring each incremental unit of storage to provide more stored energy than was provided by the previous unit. Clarifying the uncertainties surrounding the use of energy storage as a peaking resource is important because various U.S. stakeholders are making policy and investment decisions about energy storage's role in electricity systems based on limited knowledge.

The rapidly falling costs and rapidly increasing deployment of solar photovoltaic (PV) technologies further complicate the analysis of energy storage's technical potential and economic value. As the amount of electricity provided by PV becomes significant - as it has in California - the shape of the net electricity demand changes, which affects the ability of storage to provide peaking capacity. ${ }^{1}$ Yet the interactions between high PV penetrations and energy storage are also poorly understood.

In this report, we examine the potential for replacing conventional peaking capacity in California with energy storage, including analysis of the changing technical potential with increased storage deployment and the effect of PV deployment. We examine nine years of historic load data, a range of storage durations (2-8 hours), and a range of PV penetration levels $(0 \%-30 \%)$. Our analysis provides timely information to California's nation-leading energy storage and PV deployment efforts, while increasing the knowledge base available to system planners in all states and regions that might consider deploying substantial amounts of storage, PV, or both.

We explore a variety of storage durations, but focus on 4-hour storage, based on the California Public Utilities Commission's "4-hour rule"-which credits storage that can operate for 4 or more consecutive hours at maximum power output with full resource adequacy credit. Based on 9 years of historic load data, we conservatively estimate that the 4-hour rule would be limited to about 3,000 MW (assuming a 2020 peak demand of $54 \mathrm{GW}$ ). This means that beyond this point, the ability of an incremental unit of 4-hour storage to reduce peak demand would drop considerably, even assuming optimal storage dispatch. This idealized no-PV analysis provides a baseline for comparing our more realistic analysis of energy storage's potential in the presence of PV deployment.

Adding PV affects the technical potential of energy storage to meet peak demand in two ways, depending on the amount of PV deployed. Figure ES-1 plots the capacity of 4-hour storage that can provide a $100 \%$ peak demand reduction credit versus PV penetration. Under conservative assumptions, when the PV penetration is lower than about $11 \%$ (on an energy basis), the potential of 4-hour storage is lower than it would be with zero PV, because that amount of PV flattens the net load shape. However, beyond about 11\% PV penetration, PV creates a "peakier" net load shape that increases the potential of 4-hour storage. California already has enough PV to

\footnotetext{
${ }^{1}$ Net demand is equal to total demand minus the demand met by variable generation resources such as PV.
} 
meet more than $11 \%$ of annual demand, so it has reached the point at which PV increases energy storage's potential. We estimate that if California achieves $17 \% \mathrm{PV}$ penetration in 2020, the amount of storage that can provide full capacity under the 4-hour rule more than doubles compared with the no-PV case - to about 7,000 MW. The potential of energy storage continues to increase with increasing PV penetration, although at a lower rate.

These results demonstrate a synergistic relationship between energy storage deployment and PV deployment. As PV penetration increases beyond 11\%, additional PV enables the use of additional shorter-duration/lower-cost energy storage. At the same time, additional energy storage can capture more otherwise-curtailed PV generation and discharge it later as needed by the system.

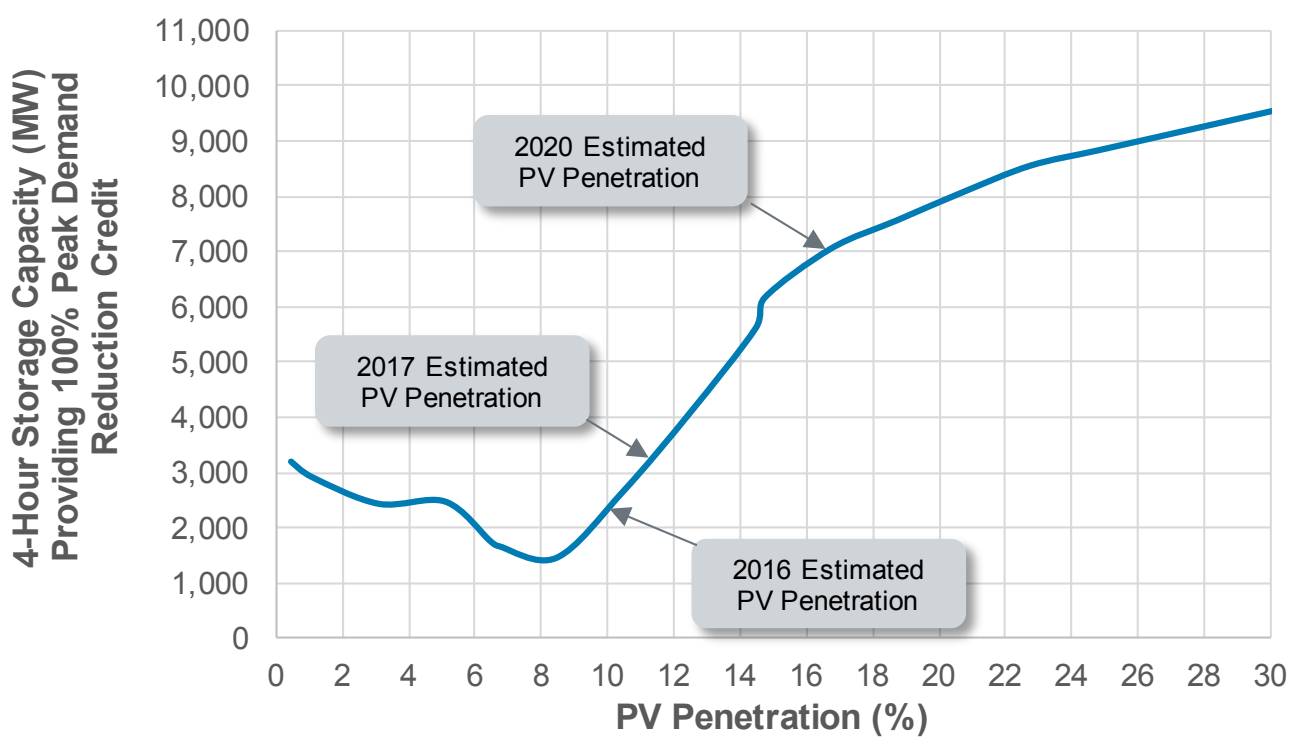

Figure ES-1. Threshold values for $100 \%$ peak demand reduction credit in California for 4-hour energy storage in 2020 (assuming a peak demand of 54 GW) 


\section{Table of Contents}

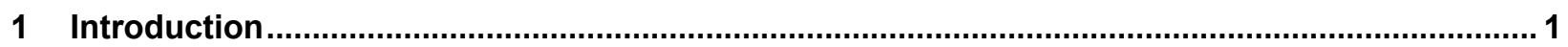

2 The Potential Market for Peaking Capacity.......................................................................... 3

3 The Need to Analyze Energy Storage's Capacity Credit under Increasing Storage and PV Penetration.

4 Analysis Method

5 Results with No PV

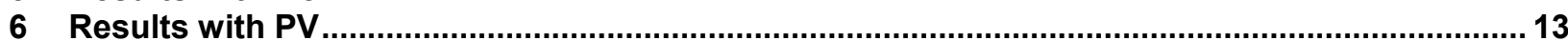

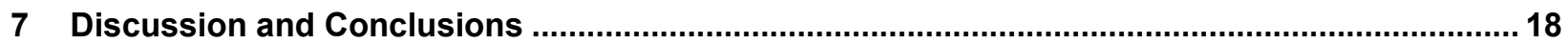

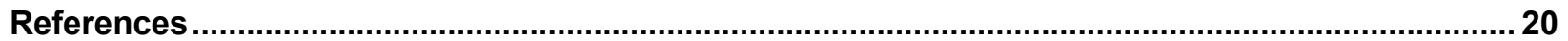

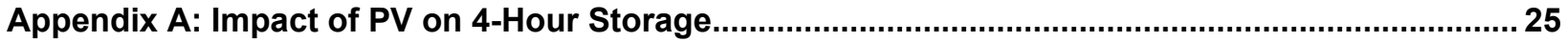

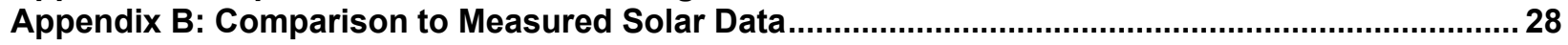




\section{List of Figures}

Figure ES-1. Threshold values for $100 \%$ peak demand reduction credit in California for 4-hour energy storage in 2020 (assuming a peak demand of $54 \mathrm{GW}$ )

Figure 1. Installation date and cumulative capacity by age for peaking capacity in California .................... 3

Figure 2. Capacity credit of storage as a function of hours of storage ...................................................... 6

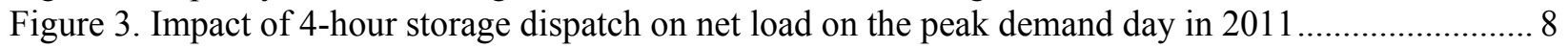

Figure 4. Limits of 8 -hour storage to reduce peak net demand due to limits in charging energy................ 8

Figure 5. Incremental peak demand reduction credit as a function of storage capacity in California using 2011 data

Figure 6. Total net peak demand reduction as a function of energy storage capacity in California using 2011 data

Figure 7. Peak demand reduction credit as a function of 4-hour storage capacity in California using 20072015 data

Figure 8. Estimated technical potential of energy storage to provide peak capacity in California in 202012

Figure 9. Distribution of simulated PV sites

Figure 10. Change in California net load shape due to PV

Figure 11. Peak demand reduction credit for 4-hour storage as a function of storage power capacity in California using 2011 load and simulated PV patterns

Figure 12. Threshold values for $100 \%$ peak demand reduction credit for 4-hour energy storage in each year (all years normalized to a peak demand of $54 \mathrm{GW}$ ) ..................................................... 16

Figure 13. Threshold values for $100 \%$ peak demand reduction credit for 4-hour energy storage in 2020 (assuming a peak demand of $54 \mathrm{GW}$ )

Figure A-1. Impact of PV on net demand shape during the 2-day period of annual peak demand using 2011 data

Figure A-2. Net CAISO load during the peak demand day, 2012-2017 (x-axis is hour of day, y-axis is net demand in MW)

Figure A-3. Threshold values for $100 \%$ peak demand reduction credit for 4-hour energy storage in each year, 2014-2017 (normalized to annual peak) using measured CAISO load and PV data.... 30 


\section{Introduction}

The cost of battery-based energy storage has declined dramatically in recent years (Schmidt et al. 2017), presenting an opportunity for energy storage to perform functions currently met by conventional generators that serve peak electricity demand. However, batteries and traditional peaking generators have very different operating characteristics. A gas turbine can run continuously for hours or days, whereas batteries typically must be recharged after a few hours of discharge. ${ }^{2}$ Thus, if batteries are to function effectively as a peaking resource, they must be able to store adequate energy and be dispatched appropriately during periods of peak demand.

Assessing the technical and economic limits to the amount of energy storage that could be deployed as peaking capacity also requires analyzing how storage changes the "shape" of the peak demand period. This interaction means that each incremental unit of storage needs to provide more stored energy than was provided by the previous unit. Thus, the contribution of additional units of energy storage towards resource adequacy will eventually decline, meaning at some point compensation for energy storage providing peaking capacity should decline as well. Clarifying these uncertainties as soon as possible could be important, because various U.S. stakeholders are making policy and investment decisions about energy storage's role in electricity systems based on limited knowledge.

The rapidly falling costs and rapidly increasing deployment of solar photovoltaic (PV) technologies (Haegel et al. 2017) further complicate the analysis of energy storage's potential. As the amount of electricity provided by PV becomes significant - as it has in California - the shape of the net electricity demand changes, which affects the ability of storage to provide peaking capacity. ${ }^{3}$ Yet the interactions between high PV penetrations and energy storage are also poorly understood.

In this report, we examine the potential for storage to serve peak electricity demand in California, including analysis of how the potential changes with increased storage and PV deployment. We examine nine years of historic load data, a range of storage durations (2-8 hours), and a range of $\mathrm{PV}$ penetration levels $(0 \%-30 \%)$.

The intent of our analysis is to provide timely information to California's energy storage and PV deployment efforts, while increasing the knowledge base available to system planners in all states and regions that might consider deploying substantial amounts of storage, PV, or both. California is the U.S. leader in deployment of both energy storage and PV. It has mandated increasing deployment of storage (CPUC 2013) and variable generation resources such as wind and solar (Green and Crume 2017). It has also proposed additional measures to require "clean" resources to meet peak demand, which could further incentivize energy storage development (Nese et al. 2017). In addition, it is a leader in developing policies related to the ability of storage to meet peak demand. The California Public Utilities Commission (CPUC) credits 4-hourcapacity storage with the ability to provide reliable peak capacity. However, as additional storage and PV are deployed, the changing shape of the net-demand curve could affect the ability of 4hour storage to meet peak demand reliably.

\footnotetext{
${ }^{2}$ This assumes firm availability of gas supply.

${ }^{3}$ Net demand is equal to total demand minus the demand met by variable generation resources such as PV.
} 
The remainder of this report is structured as follows. Section 2 discusses the size of the peakcapacity market. Section 3 describes the need to analyze energy storage's ability to meet peak demand under increasing storage and PV penetrations. Section 4 presents our analytical methods. Section 5 shows our results for a "no PV" scenario, which establishes a baseline for comparison. Section 6 shows our results under increasing PV penetrations. Section 7 offers observations and conclusions and discusses needs for additional analysis. 


\section{The Potential Market for Peaking Capacity}

In recent years, a large fraction of utility-scale storage has been deployed to provide ancillary services, including frequency regulation (DOE 2017). Frequency regulation —often referred to as simply "regulation" (EPRI 2016a) - requires generators to change output rapidly in response to relatively small unscheduled variations in electricity demand (Xu et al. 2016). Because of high utilization and limited duration requirements (typically 30 minutes or less), regulation has been a cost-effective entry point for energy storage (Xu et al. 2016). However, this market is relatively small compared with the markets for other grid services. In the California Independent System Operator (CAISO) market, which manages about $80 \%$ of California's electricity demand (FERC 2015), the average upward regulation market requirement in 2016 was $412 \mathrm{MW}$ of supply, compared with an average hourly energy demand in 2016 of 26,047 MW and a peak demand of 46,232 MW (CAISO 2017a).

Peaking capacity represents a much larger potential market for energy storage. Peaking capacity historically has been provided by a combination of simple-cycle gas turbines, gas- and oil-fired steam plants, and reciprocating engines using gas or liquid fuels (FERC 2015). To a lesser extent, pumped hydro storage plants - typically with more than 8 hours of capacity - are used to meet peak demand (DOE 2017), and early deployments of battery storage for meeting peak demand are occurring (Cardwell and Krauss 2017). However, the conventional generators providing most U.S. peak capacity today are aging, and future retirements will provide opportunities for substantial battery storage to enter this market. California currently has about $20.8 \mathrm{GW}$ of peaking generation capacity (EIA 2017), consisting of 272 internal-combustion, simple-cycle, and steam-turbine generators fired by liquid or gaseous fossil fuels. ${ }^{4}$ The installation dates for this peaking capacity are shown in Figure 1a, and the calculated cumulative capacity at various ages is shown in Figure $1 \mathrm{~b}$. About $12 \mathrm{GW}$ of capacity are at least 40 years of age. For comparison, the average retirement age of the $60 \mathrm{GW}$ of peaking plants (throughout the entire United States) that have been shut down since 1980 was 44 years.

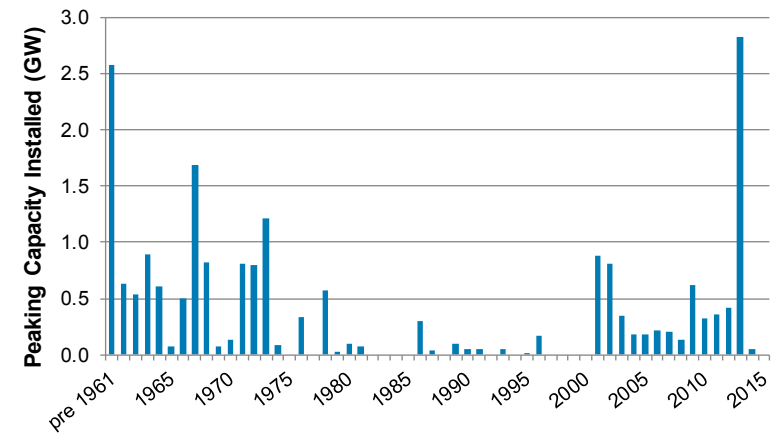

a) Installation Date

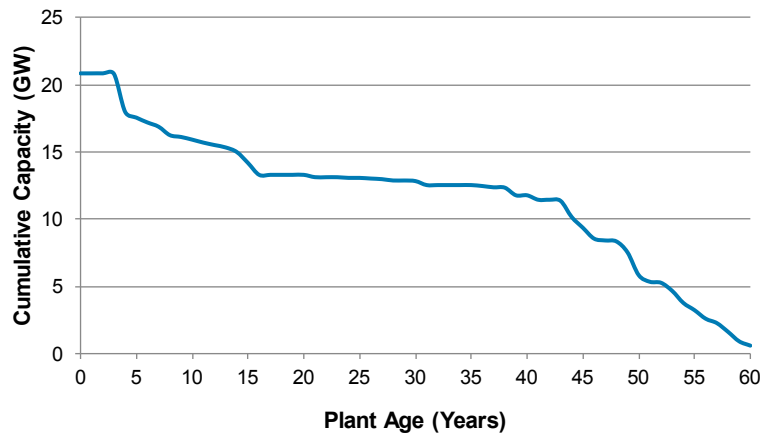

b) Cumulative Capacity by Age ${ }^{5}$

Figure 1. Installation date and cumulative capacity by age for peaking capacity in California

Assuming the existing generation fleet has the same retirement characteristics as the historic fleet, we would expect about $13 \mathrm{GW}$ of peaking capacity in California to retire over the next 20

\footnotetext{
${ }^{4}$ To identify purely peaking capacity, we use the 2015 U.S. Energy Information Administration Form 860 database and restrict our data set to those generation types listed above. We also exclude any cogeneration facilities.

${ }^{5}$ As of summer 2017.
} 
years, based only on age. This level of retirements is similar to the amount of capacity (about 11 $\mathrm{GW}$ ) required to be retired by 2029 owing to once-through cooling requirements, most of which is peaking capacity typically operating at less than $15 \%$ capacity factor (CEC 2017a). This capacity is substantially larger than the frequency regulation market for the entire United States, which is less than $5 \mathrm{GW} .{ }^{6}$ Retirements of other generation capacity and any capacity outside the state used to meet peak demand would further increase the substantial opportunity for energy storage to provide peak capacity in California over the next couple of decades.

\footnotetext{
${ }^{6}$ This figure combines the regulation market in areas with ancillary service markets (Zhou et al. 2016) and the estimated regulation requirements in areas without restructured markets (Denholm et al. 2015a).
} 


\section{The Need to Analyze Energy Storage's Capacity Credit under Increasing Storage and PV Penetration}

To provide reliable peaking capacity, energy storage must have a high "capacity credit," which reflects the ability of a resource to provide energy during periods of peak demand (Keane et al. 2011). ${ }^{7}$ To achieve a $100 \%$ capacity credit, a storage device must have sufficient duration (hours of discharge at full capacity) to carry it through the period of peak electricity demand, which is driven by the shape of the net demand curve. Historically, utilities have assigned a high capacity credit to pumped hydro storage plants, which typically have 8 or more hours of storage duration (EPRI 1976); this makes intuitive sense, because the period of peak demand is typically less than 8 hours in duration (see Section 4). However, we can find little rigorous analysis of the capacity credit of energy storage. It is less obvious whether batteries with less than 8 hours of duration could meet peak demand. It is also unclear what the "threshold" storage duration for full capacity credit might be, or how shorter-duration storage might be "derated" to the appropriate capacity credit.

Studies on the capacity credit of storage are lacking for a few reasons. First, deployments of shorter duration storage for peaking capacity to date have been limited, reducing the need for rigorous analysis. In addition, the lack of storage capacity credit analysis might be due to the difficulty of accurately modeling storage dispatch and limited availability of appropriate analytic tools.

A survey of the literature identified only a few estimates of the capacity credit of storage in California, including estimates in Sioshansi et al. (2014) and Alvarez et al. (2017). ${ }^{8}$ Sioshansi et al. (2014) include estimates of capacity credit as a function of storage duration, which are summarized as the blue curve in Figure 2. This curve represents the average of estimates from an analysis of two regions in California using multiple years of historic price and load data. The black curve in Figure 2 ("CPUC 4-hour rule") is based on resource adequacy rules for California's investor-owned utilities (CPUC 2017a). These rules require load-serving entities under CPUC jurisdiction to procure sufficient capacity to meet peak demand (Chow and Brant 2017). ${ }^{9}$ Current rules state that, for storage to be eligible, it must have "the ability to operate for at least four consecutive hours at maximum power output" (CPUC 2014). ${ }^{10}$ To create the capacity credit curve under this assumption, we divide the number of hours of energy by 4 for devices with less than 4 hours of capacity; for example, a 2-hour storage device would need to

\footnotetext{
${ }^{7}$ Technically, capacity credit is measured during the periods with the highest probability of generation being unable to meet demand. In practice, this corresponds highly to periods of peak demand, such as hot, summer afternoons in much of the U.S., including California (Madaeni et al. 2013).

${ }^{8}$ Estimates from other regions include Portland, Oregon (PGE 2016) and the Electric Reliability Council of Texas (Johal et al. 2016).

${ }^{9}$ EPRI (2016b) provides additional discussion of the CPUC resource adequacy requirements, with a particular focus on storage.

${ }^{10}$ The 2018 Resource Adequacy Guide (CPUC 2017a) refers to "Appendix B of D.14-06-050" (which we cite as CPUC 2014) to determine qualifying capacity for energy storage.
} 
discharge at $50 \%$ of nameplate power capacity for 4 hours, resulting in a $50 \%$ capacity credit. ${ }^{11}$ For simplicity, we assume this rule is applied to the remainder of California in our study.

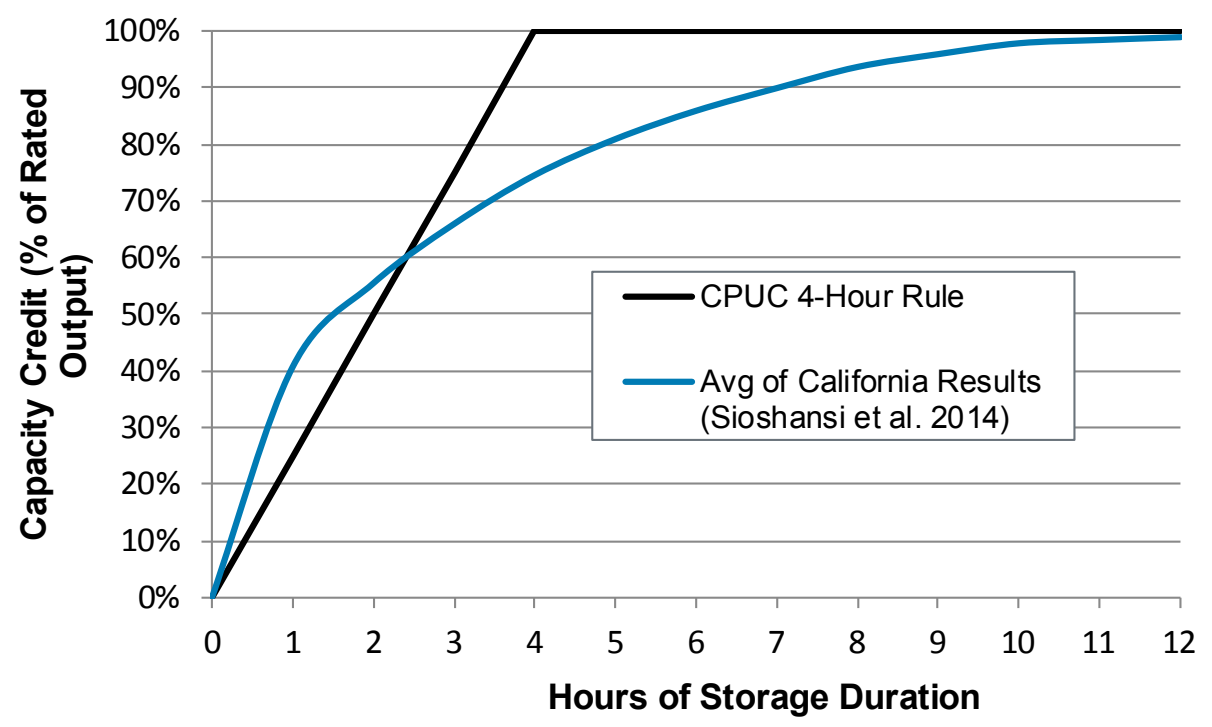

Figure 2. Capacity credit of storage as a function of hours of storage

Additional analysis is needed on the changing capacity credit of shorter-duration energy storage as a function of storage penetration in California. Of the 1,325 MW of capacity in the California storage mandate, a large fraction is expected to have 4 hours (or less) of duration, ${ }^{12}$ and additional storage is expected from publicly owned utilities as well as behind-the-meter installations (Maloney 2017, Walton 2016). However, Sioshansi et al. (2014) only consider the addition of a relatively small amount of storage, and CPUC resource adequacy documents provide little discussion of the impact of increased storage deployment. Alvarez et al. (2017) provide one relevant estimate of storage's capacity credit with increasing storage penetration in California. They estimate that about 3,000 MW of storage with 4 hours of duration should provide about $100 \%$ capacity credit, with the capacity credit falling rapidly beyond about 6,000 MW. ${ }^{13}$

Clarifying the impact of California's increasing PV deployment on energy storage's capacity credit is also important. The capacity credit estimates in Sioshansi et al. (2014) are based on historic load data that do not consider the impact of variable generation on net load shape. However, other analyses have demonstrated that PV can change the net load shape and potentially increase storage's capacity credit or reduce the storage duration needed for full capacity credit (Perez et al. 2008, Jorgenson et al. 2014, Strategen Consulting 2017).

\footnotetext{
11 The New York Independent System Operator also uses a "4-hour rule" for assessing the capacity credit of energy storage (Johal et al. 2016).

${ }^{12}$ For example, the CAISO 2014 Long-Term Procurement Plan assumes $551 \mathrm{MW}$ of 2-hour storage and $551 \mathrm{MW}$ of 4-hour storage (Eichman et al. 2015).

${ }^{13}$ Another example of a study that examines the capacity credit as a function of penetration is Shi and Luo (2017), but this study does not calculate an estimate for California.
} 


\section{Analysis Method}

We approximate the capacity credit of energy storage by evaluating the ability of energy storage to reduce the peak net demand for electricity. This is similar to the "capacity factor" approximation approach, in which the availability of a generator is determined during a limited number of hours of peak demand (Frew et al. 2017). This is also similar to evaluating energy storage's contribution to the planning reserve margin, which is typically assessed at the annual peak demand period.

Figure 3 provides an example of our method, showing the day of peak demand in California (September 6) using 2011 data with and without the addition of simulated storage. The storage is dispatched using a simple peak-shaving/valley-filling algorithm assuming perfect foresight of electricity demand and an $80 \%$ roundtrip (AC) efficiency. We incrementally add energy storage, assuming full discharge, and measure the effective reduction in net annual peak demand. We repeat this process until adding an incremental $1 \mathrm{MW}$ of energy storage can no longer reduce the annual net demand by $1 \mathrm{MW}$ owing to the limited energy capacity, measured by the "width" of the demand period. In Figure 3, we have added 4,249 MW of storage with 4 hours of duration (or $16,996 \mathrm{MWh}$ of stored energy). Up to this point, this storage capacity can reduce the annual peak demand by an amount equal to the rated capacity of the storage device (4,249 MW). Thus the 4hour device could effectively contribute to the system planning reserve margin by an amount equal to the power rating of the device, effectively replacing 4,249 MW of conventional peaking capacity assuming perfect foresight of electricity demand. However, beyond this point, the width of the demand period is greater than 4 hours. At this point, the net peak demand is $48,292 \mathrm{MW}$ from $1 \mathrm{pm}$ to $7 \mathrm{pm}$, or about 6 hours in width. (The width at this point is greater than 4 hours because during the shoulders of the peak period the device discharges below its full capacity.) To reduce the peak demand further, the 4-hour device must discharge at less than its full rating for 6 hours, which produces an effective "peak demand reduction credit" of $4 / 6$ or about $67 \%$. If additional 4-hour storage were added, it would further increase the width of the net demand period, decreasing the incremental demand reduction credit and reducing its value to the system. 


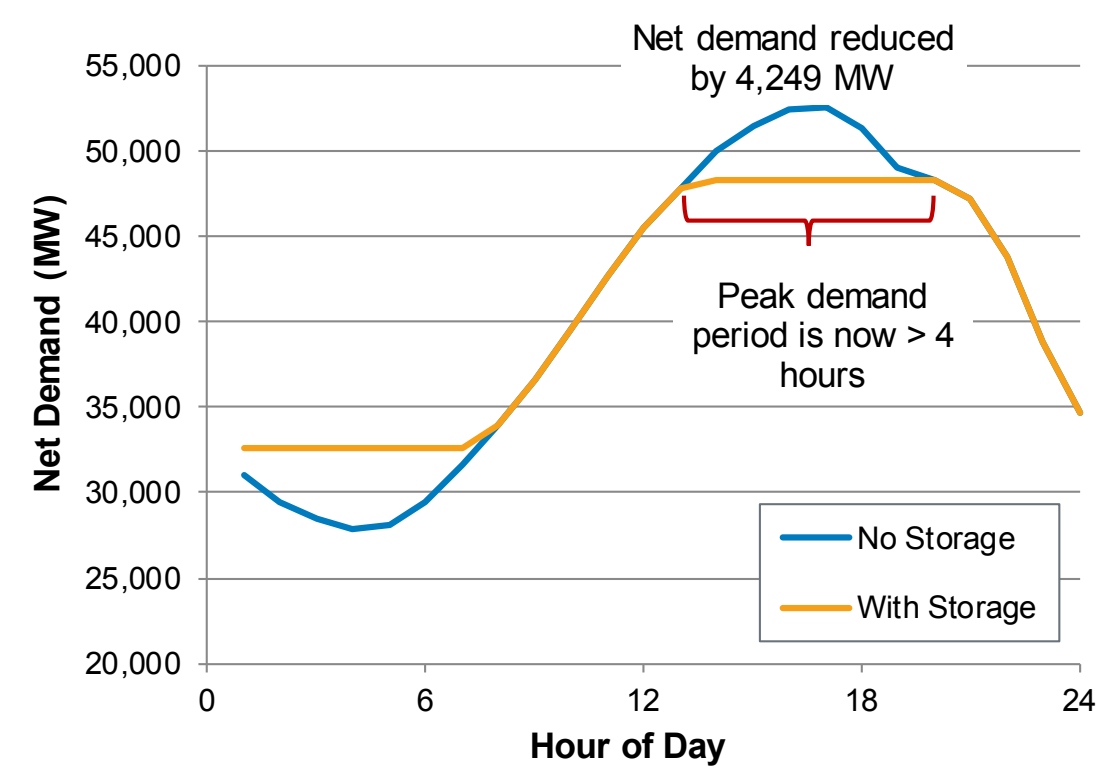

Figure 3. Impact of 4-hour storage dispatch on net load on the peak demand day in 2011

Longer-duration storage can reduce peak net demand further, but there are limits. Figure 4 shows an example (on the same day as in Figure 3) with a storage duration of 8 hours. The net peak demand is reduced to the point where the load is almost completely flat over this 24-hour period. For storage to reduce the peak demand further, it would need to charge during a previous day, requiring much longer-duration storage and the ability to forecast net demand over extended periods.

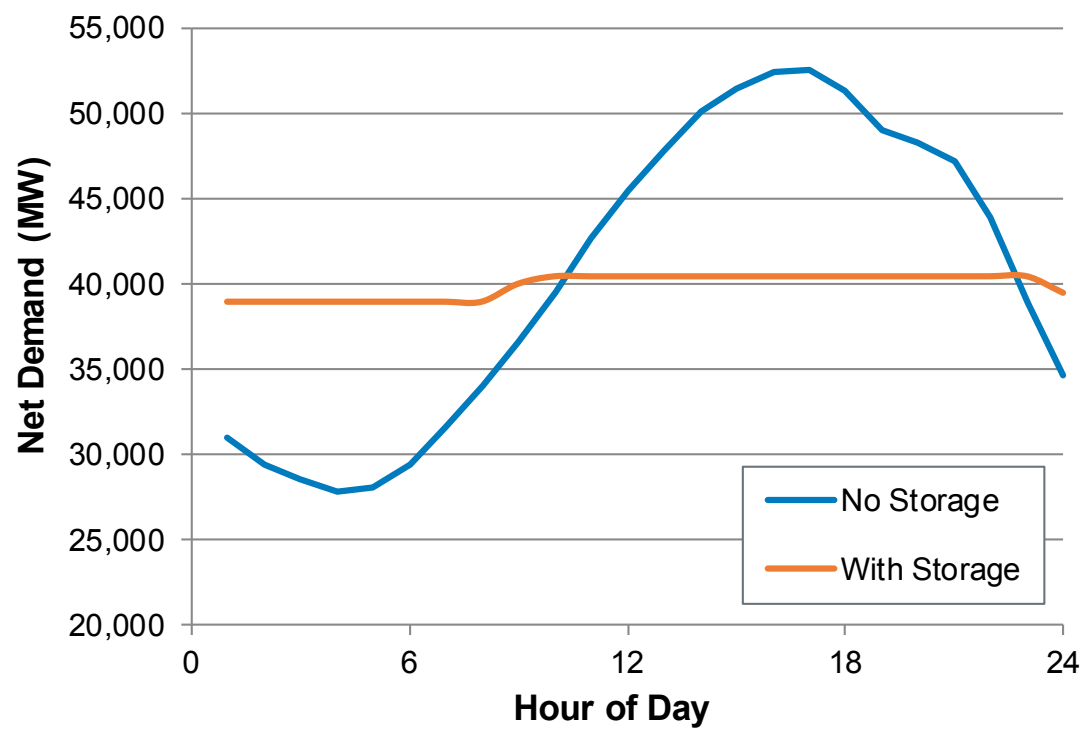

Figure 4. Limits of 8-hour storage to reduce peak net demand due to limits in charging energy

We repeat this process over a large range of storage power capacities, assuming fixed durations of $2,4,6$, and 8 hours. Storage dispatch is simulated over all hours of the year ${ }^{14}$ using the

${ }^{14}$ Although we measure the peak demand relative to the hour of annual peak, we simulate all hours of the year, because the net peak demand can be shifted to other days owing to the impacts of storage and/or PV on net load. 
National Renewable Energy Laboratory's Renewable Energy Flexibility (REFlex) model (Denholm and Hand 2011, Denholm and Margolis 2016), assuming an 80\% roundtrip efficiency and not considering storage outage rates. ${ }^{15}$ Hourly load data for 2007-2015 were derived from the Federal Energy Regulatory Commission's Form 714 database (FERC 2017) and CAISO websites. ${ }^{16}$ We include the load from all California balancing area authorities. ${ }^{17}$

Figure 5 provides an example of results using our approach with 2011 load data. Each point on the curve represents the peak demand reduction credit of an incremental unit of storage. The credit is shown as a percentage, meaning a 1-MW device would be expected to reduce the net peak demand by $1 \mathrm{MW}$ at $100 \%$, and by $0.5 \mathrm{MW}$ at $50 \%$. We also highlight two points in the figure. The point labeled "4-Hour Threshold" is the point at which the peak demand reduction credit for a 4-hour device falls to below 100\% (at 4,249 MW), as illustrated in Figure 3. The second point represents the 8-hour threshold (about 12,120 MW), as illustrated in Figure 4. All the curves follow a downward trend, with a series of step functions representing the increase in width of the net demand shapes. Using shorter time intervals (i.e., subhourly) in our simulations would tend to smooth the curves, but the general shape would stay the same.

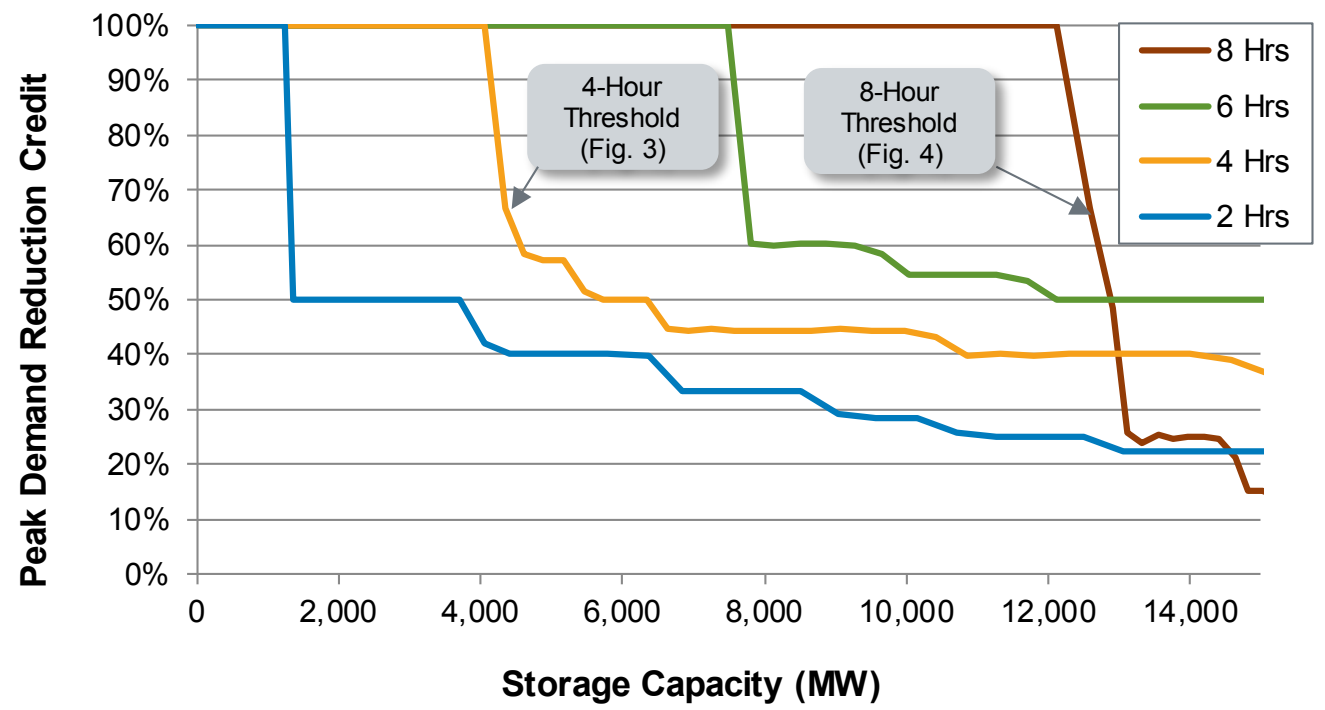

Figure 5. Incremental peak demand reduction credit as a function of storage capacity in California using 2011 data

Figure 5 also shows $100 \%$ values for a small amount of storage with 2 hours of capacity, in contrast to both the more detailed capacity credit analysis by Sioshansi et al. (2014) and the "4hour rule" shown in Figure 2. This difference is based on several factors. We assume that storage dispatch is based solely on reducing peak demand, whereas Sioshansi et al. (2014) dispatch storage based on electricity prices. Another factor is the uncertainty of peak demand periods.

\footnotetext{
${ }^{15}$ The capacity credit of conventional thermal plants (assuming no restrictions on fuel availability) is typically determined by the plant outrage rate (Sioshansi et al. 2014). A storage plant would similarly be "derated" by outages that occur during peak demand periods.

${ }^{16}$ Because the System Advisor Model (used to generate PV performance data) does not allow for years with more than 365 days, leap days were removed from the load data.

${ }^{17}$ Including CAISO, Los Angeles Department of Water and Power, Balancing Authority of Northern

California/Sacramento Municipal Utility District, Imperial Irrigation District, and Turlock Irrigation District.
} 
Although electricity demand forecasts are very accurate (Hodge et al. 2013), they are not perfect. As a mitigation against imperfect forecasts, a system planner might derate a shorter-duration storage device to ensure stored energy is available throughout the peak demand period. With these caveats in mind, we include the 2-hour case here for completeness.

Figure 6 translates the data in Figure 5 into the net reduction in peak demand as a function of installed storage capacity. When the peak demand reduction credit is $100 \%$, the curves have a linear relationship. As storage is added, at some point depending on the duration of the storage, this relationship exhibits diminishing returns. For example, as shown in the figure, it requires about $4 \mathrm{GW}$ of 4-hour storage to reduce peak net demand by $4 \mathrm{GW}$. But to reduce peak net demand by another $4 \mathrm{GW}$ requires an additional $9 \mathrm{GW}$ of 4 -hour storage.

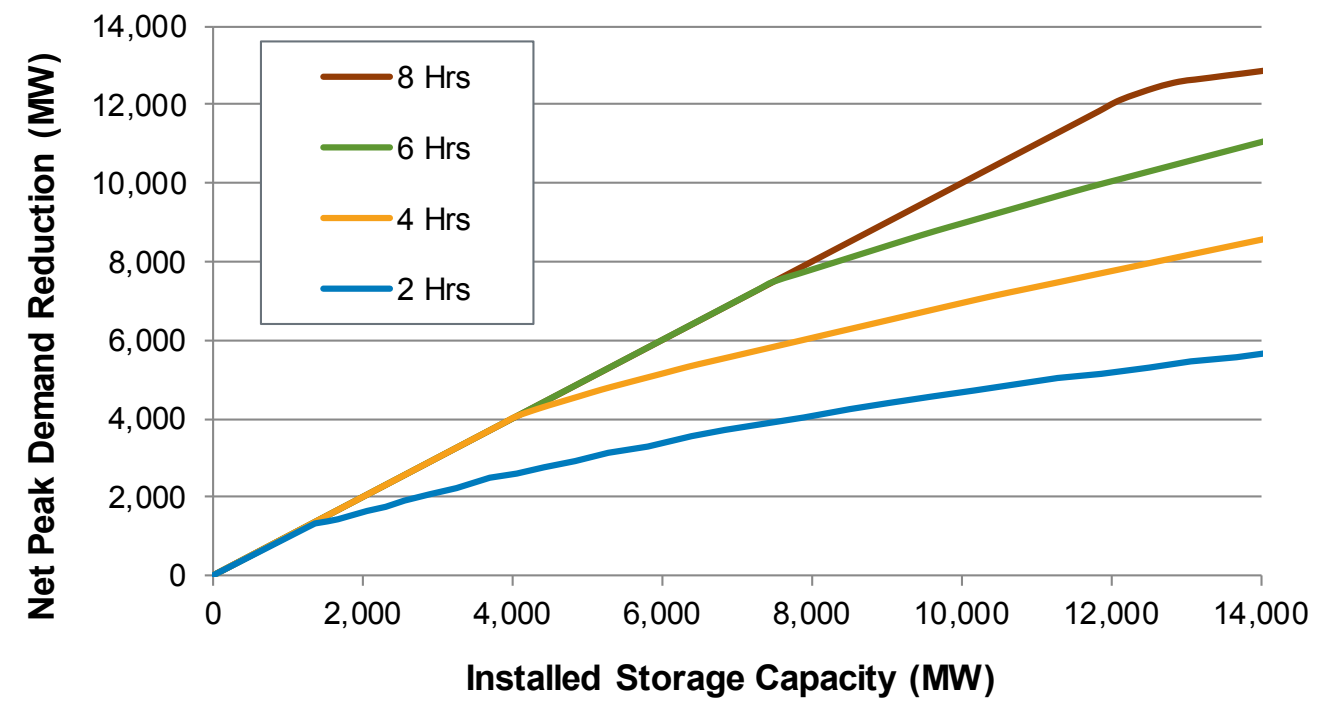

Figure 6. Total net peak demand reduction as a function of energy storage capacity in California using 2011 data 


\section{Results with No PV}

In this section, we apply the approach described in Section 4 to calculate the marginal peak demand reduction credit for each unit of storage added to the system, assuming no PV on the system. We exclude PV from this initial analysis to establish a "base case." We examine the impact of adding PV to the system in Section 6.

When analyzing the capacity credit of wind and PV, it is important to use multiple years of data to account for interannual data variations (Gami et al. 2017). Similarly, it is important to analyze multiple years of data for energy storage owing to interannual variations in demand patterns. Figure 7 shows peak demand reduction credit as a function of installed storage capacity for a 4hour storage device using our full data set. The variations by year can be attributed to changes in load patterns and load growth. To be useful for future projections, as well as to compare the effectiveness of storage across years, we normalize the results by the annual peak demand in each year. The values on the horizontal axis are measured as a fraction of the annual peak, which is provided to the right of the legend.

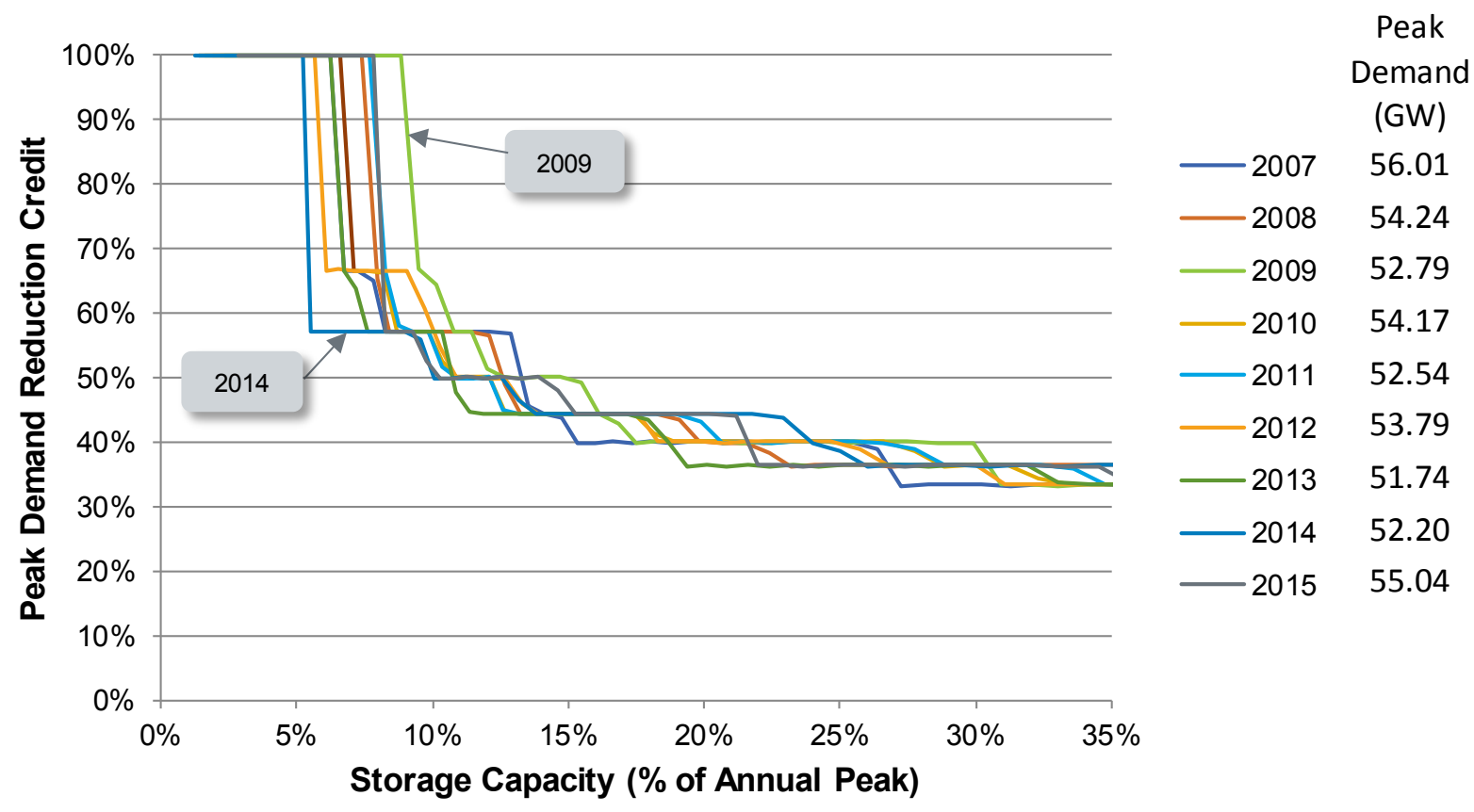

Figure 7. Peak demand reduction credit as a function of 4-hour storage capacity in California using 2007-2015 data

Figure 7 shows considerable variation from year to year. For example, using the 2009 data, we estimate that 4-hour storage could reduce the annual peak demand by about $9 \%$ before the threshold at which the 4-hour rule would be violated. Alternatively, using the 2014 data, we estimate that 4 -hour storage could reduce the peak demand by only $5.4 \%$ before the 4 -hour rule would be violated.

We use the results of this multiyear analysis to estimate the technical potential for storage to provide peaking capacity at 2, 4, 6 and 8 hours of storage duration, using a target year of 2020 . 
To estimate this 2020 potential (measured in MW), we first take the lowest (most conservative) peak demand reduction credit values across all years (which approximates a 1-in-10 planning standard).${ }^{18}$ This means we use the lower bound of the curve in Figure 7 for a 4 -hour device, and we repeat this analysis for devices with the other durations considered. We then multiply these values by the estimated peak demand in 2020 (about 54 GW) (NERC 2017).

For example, in Figure 7 the peak demand reduction credit value falls below $100 \%$ when the storage capacity equals about $5.4 \%$ of annual peak, based on the worst case curve (2014). Multiplying $54 \mathrm{GW}$ by $5.4 \%$ equals about $3 \mathrm{GW}$. Thus, we would expect the 4 -hour rule to begin to fail in California when about $3 \mathrm{GW}$ of 4-hour storage are installed. Again, this comes with the critical caveat that zero PV capacity is assumed. Repeating this calculation for all points on the curves provides the technical potential for each level of storage duration in 2020 in units of capacity (MW). The results are shown in Figure 8, where the horizontal axis represents the amount of installed storage capacity, and the vertical axis represents the incremental peak demand reduction credit at each level of storage capacity.

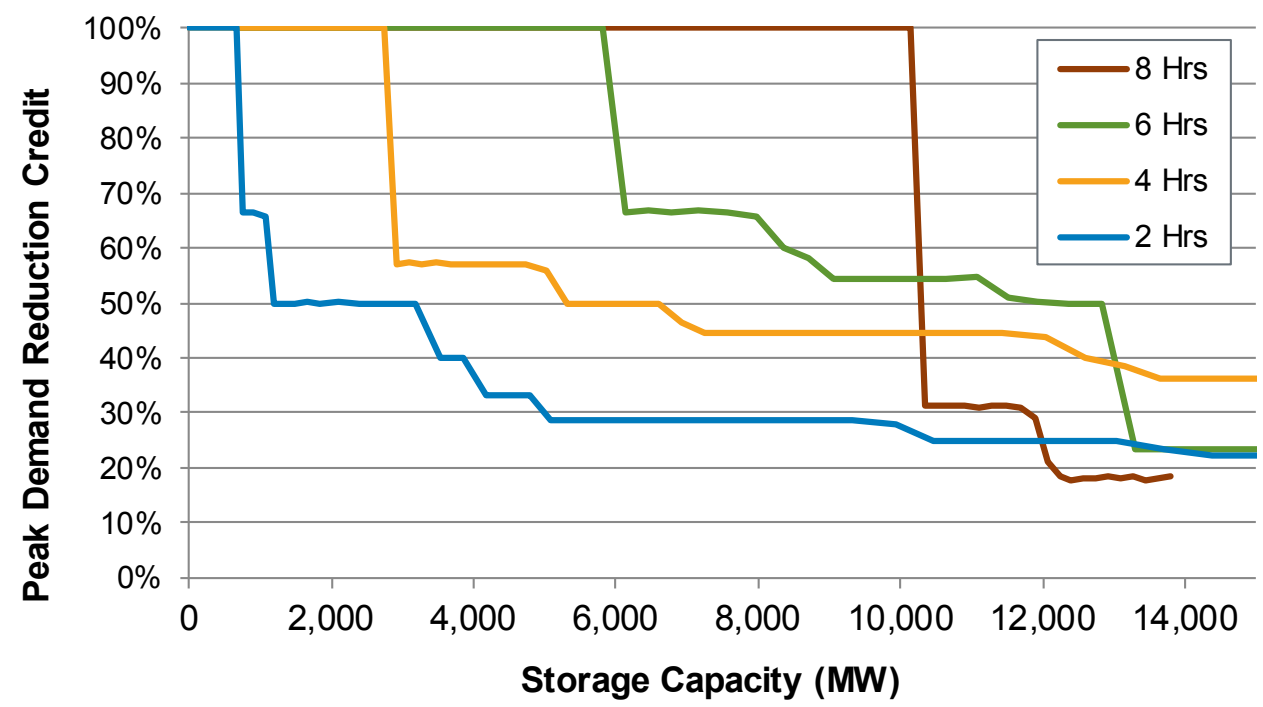

Figure 8. Estimated technical potential of energy storage to provide peak capacity in California in 2020

Historically, the capacity credit of individual generation resources has been evaluated largely independently of other resources. The results in this section demonstrate the dependence of the incremental capacity credit of energy storage on existing storage capacity. In addition, these results are of limited use without considering the impact of PV deployment, evaluated in the following section.

\footnotetext{
${ }^{18}$ For additional discussion of actual CPUC resource adequacy requirements, see CPUC (2017b) and CAISO (2017b).
} 


\section{Results with PV}

By the end of 2017, PV met an estimated $11.5 \%$ of electricity demand in California (CEC 2017b), and continued growth of the state's solar generation is projected (GTM and SEIA 2017). ${ }^{19}$ This section evaluates the impact of varying levels of PV deployment on the net demand for electricity and the ability of 4-hour storage to meet peak net demand in California. We analyze only 4-hour storage devices in this section to follow the current focus on storage devices of this size in the CPUC 4-hour resource adequacy rule discussed in Section 3.

We add simulated PV production to historical loads to achieve annual PV energy penetrations in California of up to $30 \%$. Generation of the hourly PV profiles requires two steps. First, the regional mix of installed PV is specified, including location, orientation, and type (rooftop, utility-scale, with and without tracking). The distribution of sites is directly from the Low Carbon Grid Study (Brinkman et al. 2016); it includes 246 locations throughout California and surrounding states, with $92 \%$ of the capacity deployed in California. We assume that $60 \%$ of the PV is utility-scale (with a $60 \% / 40 \%$ split between tracking and fixed-tilt systems) and $40 \%$ is deployed on rooftops with a mix of orientations. Figure 9 shows the distribution of the PV capacity.

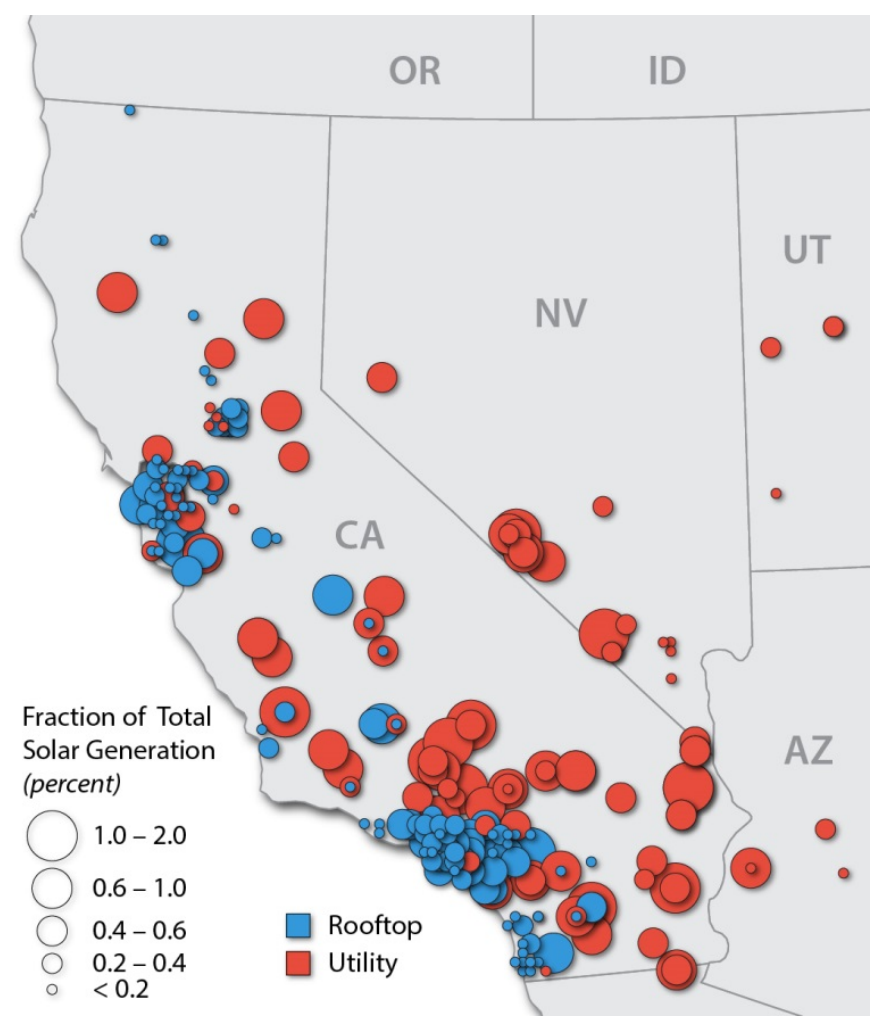

Figure 9. Distribution of simulated PV sites

Once the sites and PV types are established in each region, hourly generation profiles for 20072015 are created using the System Advisor Model (NREL 2016), with resource data from the National Solar Radiation Database (Sengupta et al. 2015). PV penetration is defined as annual PV generation (before curtailment) divided by annual electricity demand. At higher PV

${ }^{19}$ An additional 1\% was provided by CSP (CEC 2017b). 
penetrations (particularly above $20 \%$ ), there could be significant curtailment without the addition of flexibility measures such as energy storage (Denholm et al. 2015b). We also assume there is adequate transmission capacity to avoid curtailment of PV during periods of high solar output.

Figure 10 shows how increasing levels of PV $(0 \%, 5 \%, 10 \%, 15 \%$, and $20 \%$ of annual generation) change the net load shape on a peak demand day using 2011 measured load and simulated PV data on September $6 .{ }^{20}$ At low penetration, PV reduces and flattens the peak demand. As PV penetration increases, PV's impact on reducing peak demand (MW) diminishes (Mills and Wiser 2013), while it increases the "peakiness" (narrows the width) of the net peak demand.

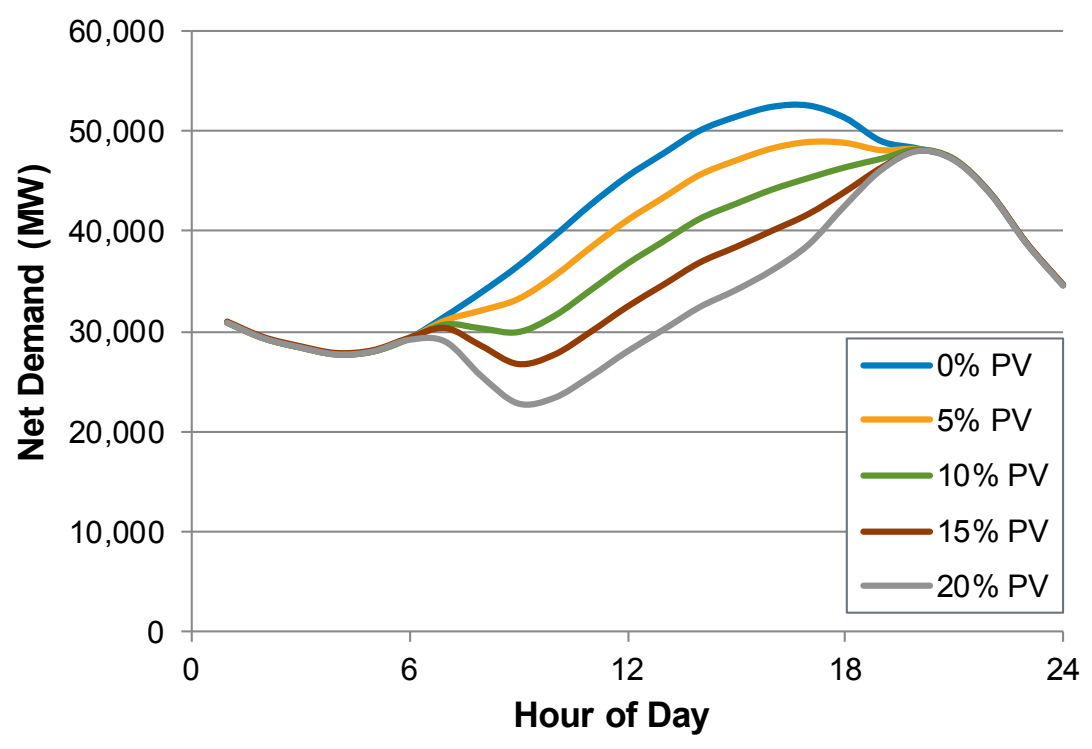

Figure 10. Change in California net load shape due to PV

Using the net load shapes for various PV penetrations, we generate peak demand reduction curves using the same approach as in Section 5. An example using 2011 load and PV patterns assuming 4-hour storage is shown in Figure 11, which provides the peak demand reduction credit for storage with zero to $30 \% \mathrm{PV}$ in $2 \%$ increments. It shows a significant impact of PV penetration on the storage threshold, i.e., where the peak demand reduction credit for 4-hour storage begins to fall below $100 \%$. At PV penetrations below about $9 \%$, the threshold is less than the zero PV case (curves are shifted to the left). Above about $9 \% \mathrm{PV}$ penetration, the threshold is greater than the zero PV case, continuing to increase out to our $30 \% \mathrm{PV}$ case.

\footnotetext{
${ }^{20}$ The electricity demand data are measured on the transmission system and represent the net load, including behindthe-meter PV. The estimated penetration of behind-the-meter PV in 2011 in California was about $0.3 \%$ based on installed net-metered PV from CSI (2018) and total generation from CEC (2017c).
} 


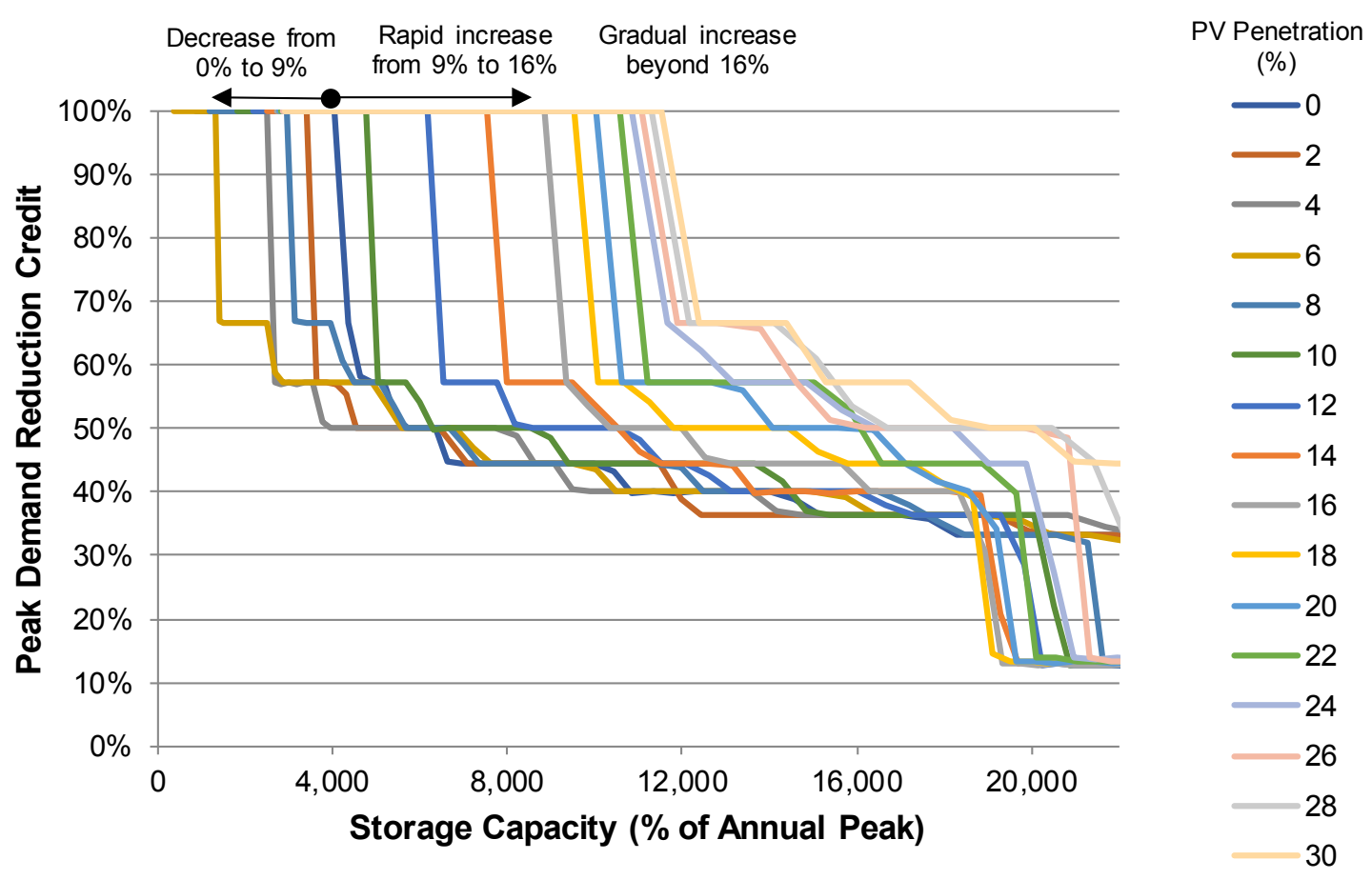

Figure 11. Peak demand reduction credit for 4-hour storage as a function of storage power capacity in California using 2011 load and simulated PV patterns

Next, we extend our analysis to determine the thresholds for 4-hour storage as a function of PV penetration for all years. Figure 12 plots the results for the nine years of data, normalized to an assumed 2020 peak demand of $54 \mathrm{GW}$, using the same approach described in Section 5. Each point represents the amount of installed capacity at which the 4-hour rule begins to fail. Because the "base" load profiles include behind-the-meter PV, we shift the curves to the right by an amount equal to the estimated behind-the-meter PV penetration in that year. For example, in 2015, behind-the-meter PV provided about $1.7 \%$ of California's electricity, so we start our zero PV curve at $1.7 \%$ for that year. ${ }^{21}$

Figure 12 shows several trends. From zero to about 5\%-8\% PV penetration, there is a decline in storage capacity that can receive a $100 \%$ peak demand reduction credit for all years evaluated owing to the "flattening" effect of PV shown in Figure 10. This is illustrated in more detail in Appendix A. At about 5\%-8\% PV penetration, PV begins to narrow the net peak demand, and around $7 \%-11 \%$ the storage capacity providing $100 \%$ peak demand reduction credit has increased past its value at zero PV and continues to increase.

\footnotetext{
${ }^{21}$ Our estimated behind-the-meter PV penetration values are 2007: 0\%, 2008: 0.1\%, 2009: 0.1\%, 2010: 0.2\%, 2011: 0.3\%, 2012: $0.7 \%, 2013: 0.8 \%, 2014: 1.1 \%$, and 2015: 1.7\%. Estimates are derived from CEC (2017b) and GTM and SEIA (2017).
} 


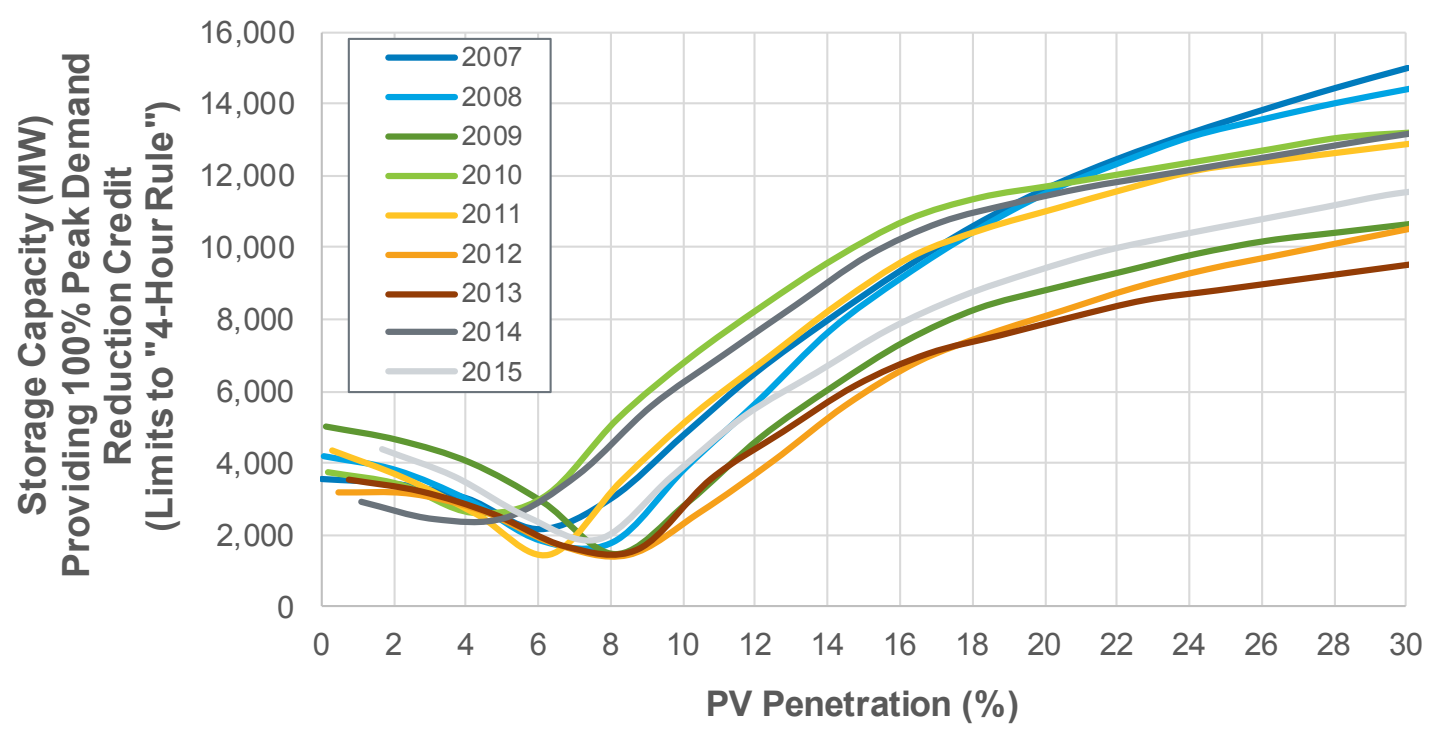

Figure 12. Threshold values for $100 \%$ peak demand reduction credit for 4 -hour energy storage in each year (all years normalized to a peak demand of $54 \mathrm{GW}$ )

Figure 13 plots the lowest value for each PV penetration level, or the worst case of our nine years of data (approximating a 1 -in-10 planning standard). ${ }^{22}$ These results imply that, at $11 \% \mathrm{PV}$ penetration (roughly the level installed in California in 2017), optimally dispatched 4-hour storage could reduce the net peak demand by about 3,000 MW with full peak demand reduction credit - about the same as at zero PV penetration. We expect the amount of 4-hour storage that could receive a full peak demand reduction credit to grow with greater PV deployment. Assuming a 2020 PV penetration of 17\%, California could accommodate about 7,000 MW of 4hour storage receiving a full peak demand reduction credit, more than doubling the amount estimated in the $2016-2017$ period. $^{23}$

\footnotetext{
${ }^{22}$ The small discontinuities are due to the use of multiple years of data. They represent points where the most conservative value moves from one year to another.

${ }^{23}$ One estimate for PV penetration in California in 2020 is about $28 \mathrm{GW}$ (GTM and SEIA 2017), leading to about an $17 \%$ penetration in 2020, assuming limited load growth.
} 


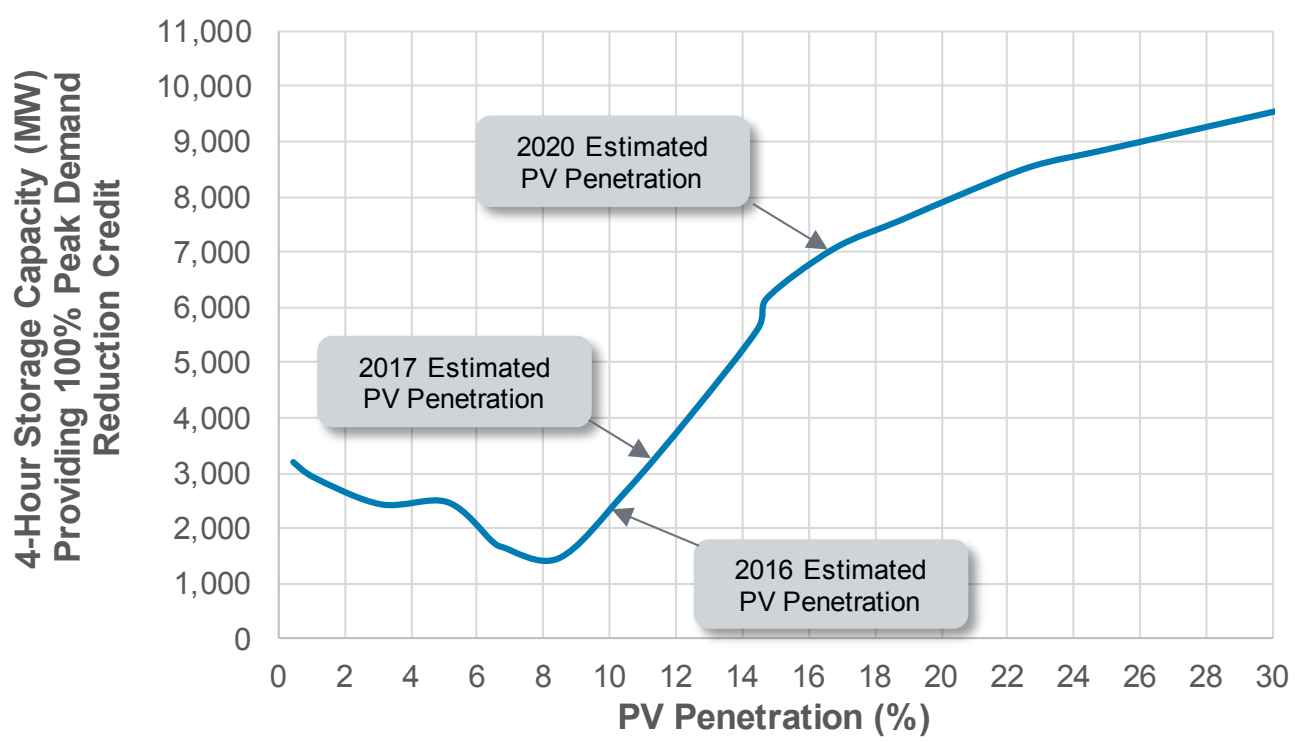

Figure 13. Threshold values for $100 \%$ peak demand reduction credit for 4 -hour energy storage in 2020 (assuming a peak demand of 54 GW)

Additional analysis and data will be needed to verify these results in California and other U.S. regions. For example, PV is only now reaching penetration levels that enable use of measured output data for validation. Analysis using recent measured PV output data from California supports the trends observed in Figure 13, as discussed in Appendix B. However, additional years of data will provide greater confidence that utilities, system planners, and regulators can rely on PV output to reduce the storage duration needed to meet peak demand.

The results in Figure 13 demonstrate one element of the potential synergy between PV and energy storage - the combined ability of these technologies to decrease the net peak demand. Without PV, 4-hour storage can only reduce the peak net demand in California by about $3 \mathrm{GW}$ before the peak demand reduction credit of storage falls rapidly, reducing its value substantially. Likewise, without storage (or other demand shifting), PV can only reduce the peak net demand in California by about $4 \mathrm{GW}$ (illustrated in Figure 10). Therefore, without considering the impacts of combining these technologies, this produces a potential peak net demand reduction of about $7 \mathrm{GW}$. However, at assumed 2020 levels of PV penetration, the potential of 4-hour storage (at $100 \%$ peak demand reduction credit) has been increased by an additional $4 \mathrm{GW}$, resulting in a greater than $50 \%$ increase in the combined ability of $\mathrm{PV}$ and storage to reduce peak net demand. In combination, PV increases the technical potential of energy storage to provide peaking capacity and reduces the cost of energy storage by reducing the duration needed. Storage also benefits PV by providing a mechanism to absorb otherwise low-value or curtailed PV energy and discharge it later as needed by the system (Denholm and Margolis 2016). Together, declining costs for both technologies may create a positive feedback effect on deployment, allowing much greater overall penetration of both PV and storage (Cole et al. 2017). 


\section{Discussion and Conclusions}

Historically, the capacity credit of a generation resource was evaluated independently of penetration of that resource, or of other resources on the system. The introduction of variable generation resources such as PV has demonstrated the need to consider the impact of highly correlated resources on capacity credit. We find that storage has a similar challenge, with a declining contribution to resource adequacy, as measured by its ability to reduce peak demand. Based on nine years of historic load data in California, our preliminary analysis demonstrates that in our hypothetical "no PV" case, 4-hour storage can reduce peak demand at the full rated capacity of the device until the point where there are about $3 \mathrm{GW}$ of installed storage capacity, assuming a 2020 peak demand of $54 \mathrm{GW}$. Beyond this point, the ability of an incremental unit of 4-hour storage to reduce peak demand would drop considerably, implying that the 4-hour rule would break down at this point, even assuming optimal storage dispatch. This idealized no-PV analysis provides a baseline for comparing our more realistic analysis of energy storage's potential in the presence of PV deployment.

Adding PV affects the technical potential of energy storage to meet peak demand in two ways, depending on the amount of PV deployed. Under conservative assumptions, when the PV penetration is lower than about $11 \%$ (on an energy basis), the potential of 4-hour storage is lower than it would be with zero PV, because that amount of PV flattens the net load shape. However, beyond about 11\% PV penetration, PV creates a "peakier" net load shape that increases the potential of 4-hour storage. California already has enough PV to meet more than $11 \%$ of annual demand, so it has reached the point at which PV increases energy storage's potential. We estimate that when PV is at $17 \%$ penetration (i.e., as projected for California in 2020) the amount of storage that can provide full capacity under the 4-hour rule more than doubles compared with the no-PV case - to about 7,000 MW (equivalent to about $13 \%$ of the projected 2020 annual prePV peak demand). The potential of energy storage continues to increase with increasing PV penetration, although at a lower rate.

These results demonstrate a synergistic relationship between energy storage deployment and PV deployment. As PV penetration increases beyond 11\%, additional PV enables the use of additional shorter-duration/lower-cost energy storage. For example, about 11,000 MW of capacity is expected to be retired in California by 2029 due to once-through-cooling requirements. Much of this capacity is peaking capacity, and our analysis implies that a large fraction of this capacity could be replaced with 4-hour storage assuming continued costreductions in storage and continued growth in PV installations (and adequate transmission). At the same time, additional energy storage can capture more otherwise-curtailed PV generation and discharge it as needed by the system, including during periods of peak demand.

Our results provide useful insights into how storage and PV interact; however, there are a number of important directions for future research. One would be to explore how our results are impacted by relaxing the assumptions of optimal storage dispatch and perfect forecasts for both load and PV generation (which are a prerequisite for optimal storage dispatch). Ongoing efforts to improve storage scheduling under uncertainty will enable improved assessment of storage's realistic ability to meet peak demand reliably (Alvarez et al. 2017). Another area for future work would be to explore how behind-the-meter storage and PV could present additional opportunities or challenges. Existing tariff structures may not send the proper signals; thus, if behind-the-meter 
storage and PV are not dispatched to reduce net demand at the system level, their ability to provide resource adequacy capacity may be diminished (Sioshansi et al. 2012). Finally, it would be helpful to understand how future load shapes are likely to evolve given increased electric vehicle deployment, increased use of demand response and energy efficiency, climate change (Auffhammer et al. 2017), and other factors. 


\section{References}

Alvarez, A., W. Dong, B. Moradzadeh, C. Nolen, R. Anderson, T. Edmunds, J. Grosh, D. Rajan, K. Carden, N. Wintermantel, P. Patel, A. Krasny, A. Tuohy, E. Ela, E. Lannoye, and Q. Wang. 2017. Role of Operating Flexibility in Planning Studies. CPUC/California Energy System for the $21^{\text {st }}$ Century. http://docs.cpuc.ca.gov/PublishedDocs/Efile/G000/M195/K586/195586923.PDF

Auffhammer, M., P. Baylis, C.H. Hausman. 2017. "Climate change is projected to have severe impacts on the frequency and intensity of peak electricity demand across the United States." PNAS, 114 (8).

Brinkman, G., J. Jorgenson, A. Ehlen, and J.H. Caldwell. 2016. California 2030 Low Carbon Grid Study: Analysis of a 50\% Emission Reduction in California. NREL/TP-6A20-64884.

Golden, CO: National Renewable Energy Laboratory.

http://www.nrel.gov/docs/fy16osti/64884.pdf

CAISO (California Independent System Operator). 2017a. 2016 Annual Report on Market Issues and Performance. Folsom, CA: CAISO.

CAISO (California Independent System Operator). 2017b. Final Manual: 2019 Local Capacity Area Technical Study. Folsom, CA: CAISO.

http://www.caiso.com/Documents/2019LocalCapacityRequirementsFinalStudyManualdocx.pdf

Cardwell, D., and C. Krauss. 2017. “A Big Test for Big Batteries.” New York Times, January 14, 2017.

CEC (California Energy Commission). 2017a. Once-Through Cooling Phase-Out. Sacramento: CEC.

http:/www.energy.ca.gov/renewables/tracking_progress/documents/once through_cooling.pdf

CEC (California Energy Commission). 2017b. "Total System Electric Generation.” Accessed December 2017. http://www.energy.ca.gov/almanac/electricity_data/total_system power.html

CEC (California Energy Commission). 2017c. "California Electrical Energy Generation." Accessed December 2017.

http://www.energy.ca.gov/almanac/electricity_data/electricity_generation.html

Chow, L., and S. Brant. 2017. The 2016 Resource Adequacy Report. San Francisco: California Public Utilities Commission.

http:/www.cpuc.ca.gov/WorkArea/DownloadAsset.aspx?id=6442453942

Cochran, J., P. Denholm, B. Speer, and M. Miller. 2015. Grid Integration and the Carrying

Capacity of the U.S. Grid to Incorporate Variable Renewable Energy. NREL/TP-6A20-62607.

Golden, CO: National Renewable Energy Laboratory.

http://www.nrel.gov/docs/fy15osti/62607.pdf 
Cole, W., B. Frew, P. Gagnon, J. Richards, Y. Sun, J. Zuboy, M. Woodhouse, and R. Margolis. 2017. SunShot 2030 for Photovoltaics (PV): Envisioning a Low-cost PV Future. DOE/GO$102017-4954$.

CPUC (California Public Utilities Commission). 2013. Decision 13-10-040: Decision Adopting Energy Storage Procurement Framework and Design Program. October 17, 2013. http://docs.cpuc.ca.gov/PublishedDocs/Published/G000/M079/K533/79533378.PDF

CPUC. (California Public Utilities Commission). 2014. Decision 14-06-050: Decision Adopting Local Procurement and Flexible Capacity Obligations for 2015, and Further Refining the Resource Adequacy Program. June 26, 2014. http://docs.cpuc.ca.gov/PublishedDocs/Published/G000/M097/K619/97619935.PDF

CPUC (California Public Utilities Commission). 2017a. 2018 Filing Guide for System, Local and Flexible Resource Adequacy (RA) Compliance Filings. September 26, 2017.

http://www.cpuc.ca.gov/WorkArea/DownloadAsset.aspx?id=6442454920

CPUC. (California Public Utilities Commission). 2017b. "Resource Adequacy.” Accessed December 2017. http://www.cpuc.ca.gov/RA/

CSI (California Solar Initiative). 2018. "California Distributed Generation Statistics.” Accessed January 2018. https://www.californiadgstats.ca.gov/

Denholm, P., and M. Hand. 2011. "Grid Flexibility and Storage Required to Achieve Very High Penetration of Variable Renewable Electricity.” Energy Policy 39:1817-30.

Denholm, P., and R. Margolis. 2016. Energy Storage Requirements for Achieving 50\% Solar Photovoltaic Energy Penetration in California. NREL/TP-6A20-66595. Golden, CO: National Renewable Energy Laboratory.

Denholm, P., J. Eichman, T. Markel, and O. Ma. 2015a. Summary of Market Opportunities for Electric Vehicles and Dispatchable Load in Electrolyzers. NREL/TP-6A20-64172. Golden, CO: National Renewable Energy Laboratory.

Denholm, P., M. O’Connell, G. Brinkman, and J. Jorgenson. 2015b. Overgeneration from Solar Energy in California: A Field Guide to the Duck Chart. NREL/TP-6A20-65023. Golden, CO: National Renewable Energy Laboratory.

DOE (U.S. Department of Energy). 2017. “DOE Global Energy Storage Database.” Accessed September 2017. http://www.energystorageexchange.org/

EIA (U.S. Energy Information Administration). 2017. Annual Energy Outlook 2017.

Washington, DC: EIA. https://www.eia.gov/outlooks/aeo/

Eichman, J., P. Denholm, J. Jorgenson, and U. Helman. 2015. Operational Benefits of Meeting California's Energy Storage Targets. NREL/TP- 5400-65061. Golden, CO: National Renewable Energy Laboratory. http://www.nrel.gov/docs/fy16osti/65061.pdf 
EPRI (Electric Power Research Institute). 1976. Assessment of Energy Storage Systems Suitable for Use by Electric Utilities. EPRI-EM-264. Palo Alto, CA: EPRI.

EPRI (Electric Power Research Institute). 2016a. "Wholesale Electricity Market Design Initiatives in the United States: Survey and Research Needs." 30020009273. Palo Alto, CA: EPRI.

EPRI (Electric Power Research Institute). 2016b. Energy Storage Valuation in California:

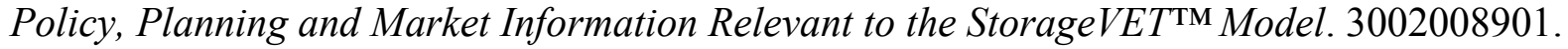
Palo Alto, CA: EPRI.

FERC (Federal Energy Regulatory Commission). 2015. Energy Primer A Handbook of Energy Market Basics. Washington, DC: FERC. https://www.ferc.gov/market-oversight/guide/energyprimer.pdf

FERC (Federal Energy Regulatory Commission). 2017. "Form No. 714 - Annual Electric Balancing Authority Area and Planning Area Report.” http://www.ferc.gov/docsfiling/forms/form-714/data.asp

Frew, B., W. Cole, Y. Sun, J. Richards, and T. Mai. 2017. 8760-Based Method for Representing Variable Generation Capacity Value in Capacity Expansion Models. NREL/CP-6A20-68869. Golden, CO: National Renewable Energy Laboratory.

Gami, D., R. Sioshansi, and P. Denholm. 2017 "Data Challenges in Estimating the Capacity Value of Solar Photovoltaics." IEEE Transactions on Photovoltaics 7(4): 1065-73.

Green, L., and C. Crume. 2017. Renewables Portfolio Standard Eligibility Guidebook, Ninth Edition. CEC-300-2016-006-ED9-CMFREV. Sacramento: California Energy Commission.

GTM and SEIA (Greentech Media and Solar Energy Industries Association). 2017. Q3 Market Report. GTM and SEIA.

Haegel, N. M., R. Margolis, T. Buonassisi, et al. 2017. "Terawatt-scale photovoltaics: Trajectories and Challenges." Science 356 (6334): 141-143.

Hodge, B.M., D. Lew, and M. Milligan. 2013. "Short-Term Load Forecasting Error Distributions and Implications for Renewable Integration Studies." Presented at the IEEE Green Technologies Conference, Denver, Colorado, April 4-5, 2013.

Johal, H., D.F. Tome, and K. Collison. 2016. Unlocking the Hidden (Capacity) Value in Energy Storage. Fairfax, VA: ICF.

Jorgenson, J., P. Denholm, and M. Mehos. 2014. Estimating the Value of Utility-Scale Solar Technologies in California under a 40\% Renewable Portfolio Standard. TP-6A20-61685. Golden, CO: National Renewable Energy Laboratory.

Keane, A., M. Milligan, C.J. Dent, B. Hasche, C. D’Annunzio, K. Dragoon, and M. O'Malley. 2011. “Capacity Value of Wind Power.” IEEE Transactions on Power Systems 26(2): 564-72. 
Madaeni, S. H., R. Sioshansi, and P. Denholm. 2013. "Comparing Capacity Value Estimation Techniques for Photovoltaic Solar Power.” IEEE Journal of Photovoltaics 3(1): 407-415.

Maloney, P. 2017. "California PUC Finalizes New 500 MW BTM Battery Storage Mandate." Utility Dive, May 4, 2017. https://www.utilitydive.com/news/california-puc-finalizes-new-500mw-btm-battery-storage-mandate/441901/

Mills, A.D. and R. H. Wiser. 2013. "Changes in the Economic Value of Photovoltaic Generation at High Penetration Levels: A Pilot Case Study of California," IEEE Journal of Photovoltaics 3(4): 1394-1402.

Nese, B., B. Orion, and P. Florez. 2017. "California Lawmakers Introduce Clean Peak Standard Legislation." Renewable + Law, April 4, 2017. https://www.lawofrenewableenergy.com/2017/04/articles/energy-policy/california-lawmakersintroduce-clean-peak-standard-legislation/

NREL (National Renewable Energy Laboratory). 2016. "System Advisor Model Version 2016.3.14 (SAM 2016.3.14).” https://sam.nrel.gov/content/downloads.

NERC (North American Electricity Reliability Corporation). 2017. 2017 Long-Term Reliability Assessment.

http://www.nerc.com/pa/RAPA/ra/Reliability\%20Assessments\%20DL/NERC LTRA 12132017 Final.pdf

Perez, R., M. Taylor, T. Hoff, and J.P. Ross. 2008. "Reaching Consensus in the Definition of Photovoltaics Capacity Credit in the USA: A Practical Application of Satellite-Derived Solar Resource Data." IEEE Journal of Selected Topics in Applied Earth Observations and Remote Sensing 1(1): 28-33. http://dx.doi.org/10.1109/JSTARS.2008.2004362

PGE (Portland General Electric). 2016. Integrated Resource Plan.

https://www.portlandgeneral.com/-/media/public/our-company/energy-strategy/documents/2016irp.pdf?la=en

Schmidt, O., A. Hawkes, A. Gambhir, and I. Staffell. 2017. "The future cost of electrical energy storage based on experience rates." Nature Energy 2, 17110.

Sengupta, M., A. Weekley, A. Habte, A. Lopez, C. Molling, and A. Heidinger. 2015. Validation of the National Solar Radiation Database (NSRDB) (2005-2012). NREL/CP-5D00-64981.

Golden, CO: National Renewable Energy Laboratory.

Shi, N., and Y. Luo. 2017. "Capacity Value of Energy Storage Considering Control Strategies." PLoS ONE 12(5): e0178466. https://doi.org/10.1371/journal.pone.0178466

Sioshansi, R., S.H. Madaeni, and P. Denholm. 2014. “A Dynamic Programming Approach to Estimate the Capacity Value of Energy Storage.” IEEE Transactions on Power Systems 29(1): 395-403. 
Sioshansi, R., P. Denholm, and T. Jenkin. 2012. "Market and Policy Barriers to Deployment of Energy Storage." Economics of Energy and Environmental Policy 1(2): 47-63.

Strategen Consulting. 2017. New York City's Aging Power Plants: Risks, Replacement Options, and the Role of Energy Storage. Berkeley, CA: Strategen Consulting. https://www.strategen.com/s/Strategen-NYC-Power-Plants-and-Energy-Storage-92020173mgr.pdf

Walton, R. 2016. "Facing Stricter Climate Goals, California Passes 4 Bills to Boost Energy Storage." Utility Dive, September 2, 2016. https://www.utilitydive.com/news/facing-stricterclimate-goals-california-passes-4-bills-to-boost-energy-st/425671/

Xu, B., Y. Dvorkin, D.S. Kirschen, C.A. Silva-Monroy, and J. Watson. 2016. "A Comparison of Policies on the Participation of Storage in U.S. Frequency Regulation Markets." Presented at the 2016 IEEE Power and Energy Society General Meeting (PESGM), pp. 1-5. DOI:

10.1109/PESGM.2016.7741531

Zhou, A., T. Levin, and G. Conzelmann. 2016. Survey of U.S. Ancillary Services Markets. ANL/ESD-16/1. Argonne, IL: Argonne National Laboratory.

http://www.ipd.anl.gov/anlpubs/2016/01/124217.pdf 


\section{Appendix A: Impact of PV on 4-Hour Storage}

Figure 3 illustrated our method for determining the limits to 4-hour storage on the peak demand day in 2011 (September 6) for the zero PV case. Figure 10 showed the impact of PV on net demand on the same day. Here we show the impact of increasing levels of PV deployment on the ability of 4-hour storage to reduce the net peak demand. Figure A-1 shows this progression from zero to $20 \% \mathrm{PV}$ in 5\% increments. Each panel shows the results for two days (September 5-6, 2011), which includes the day with the highest peak demand (Sept. 6). The figures show the net demand before and after the addition of storage, and the amount of storage that can be added before the incremental peak demand reduction credit falls below $100 \%$. The peak demand reduction threshold for 4-hour storage is 4,249 $\mathrm{MW}$ at zero PV, then declines to 1,937 MW at $5 \% \mathrm{PV}$, and increases to $4,935 \mathrm{MW}$ at $10 \% \mathrm{PV}, 8,462 \mathrm{MW}$ at $15 \% \mathrm{PV}$, and $10,372 \mathrm{MW}$ at $20 \%$ $\mathrm{PV}$. This example, clearly illustrates how the narrowing of the peak at higher PV penetration levels is synergistic with 4-hour storage.

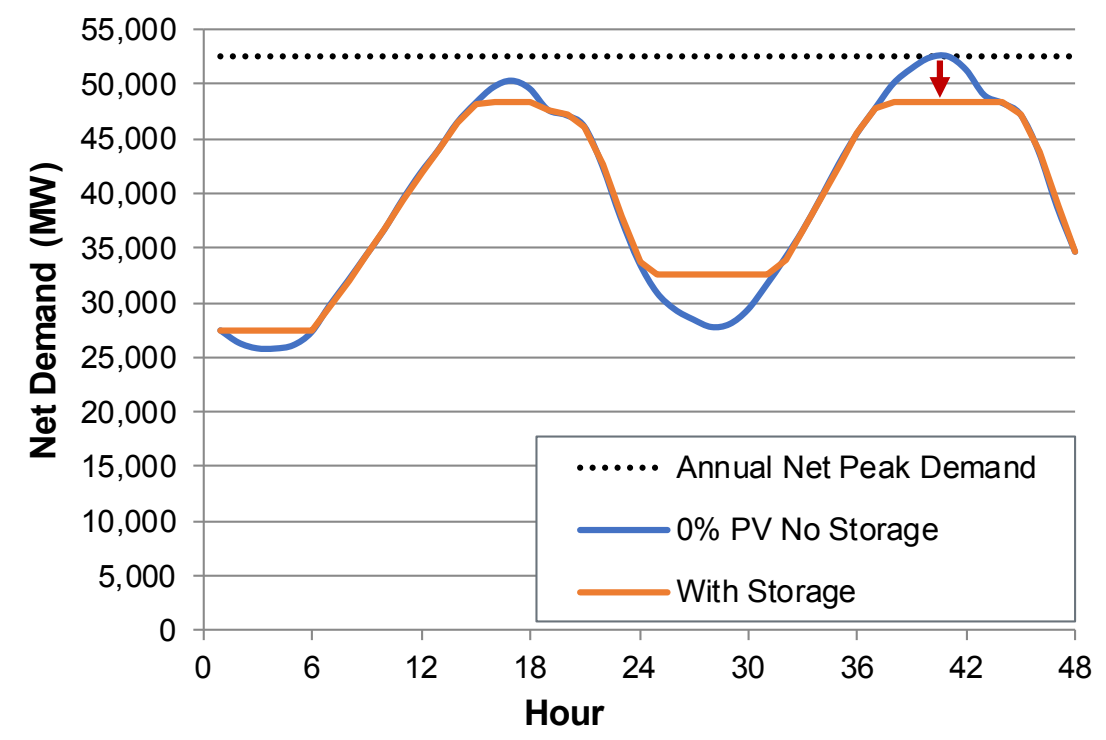

Zero PV. Peak demand occurs on September 6 (day 2) and is 52,540 MW. Peak demand reduction with 4 -hr storage at $100 \%$ credit is 4,249 MW. Annual net peak demand is reduced to $48,292 \mathrm{MW}$. Storage is not completely utilized on day one so could have had additional charge/discharge for greater price arbitrage. 


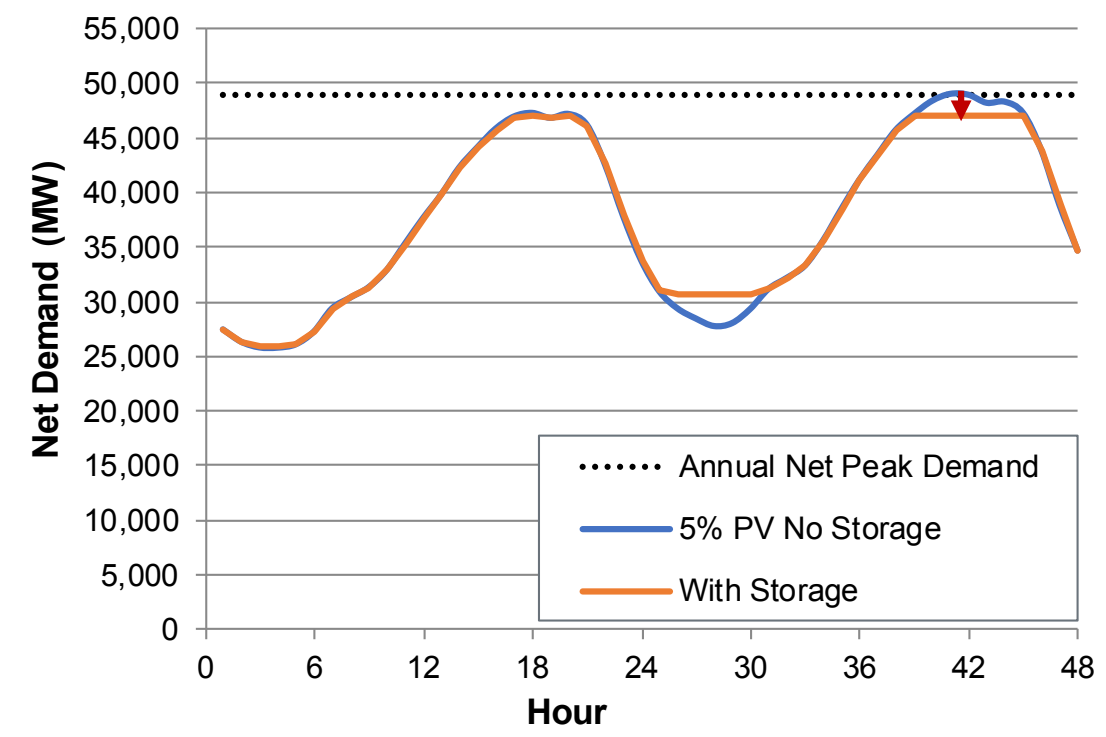

$5 \% \mathrm{PV}$. PV generation has reduced net peak demand has been reduced to $48,940 \mathrm{MW}$. The peak shape is clipped (flattened) compared to zero PV case. Peak demand reduction of 4 -hr storage at $100 \%$ credit is 1,937 MW (less than with zero PV).

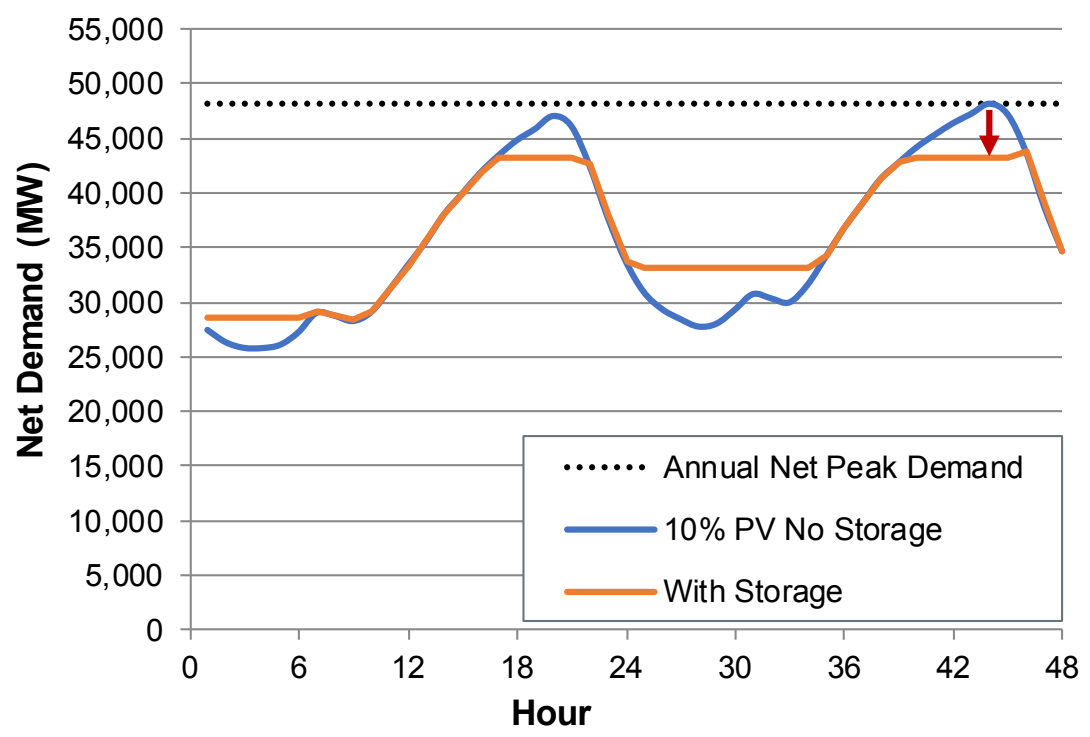

$10 \%$ PV. PV generation has reduced net peak demand has been reduced to 48,172 MW. Peak demand shape has been narrowed relative to previous cases. Peak demand reduction with 4-hr storage at $100 \%$ credit has increased to $4,935 \mathrm{MW}$, a small increase relative to the zero PV case. 


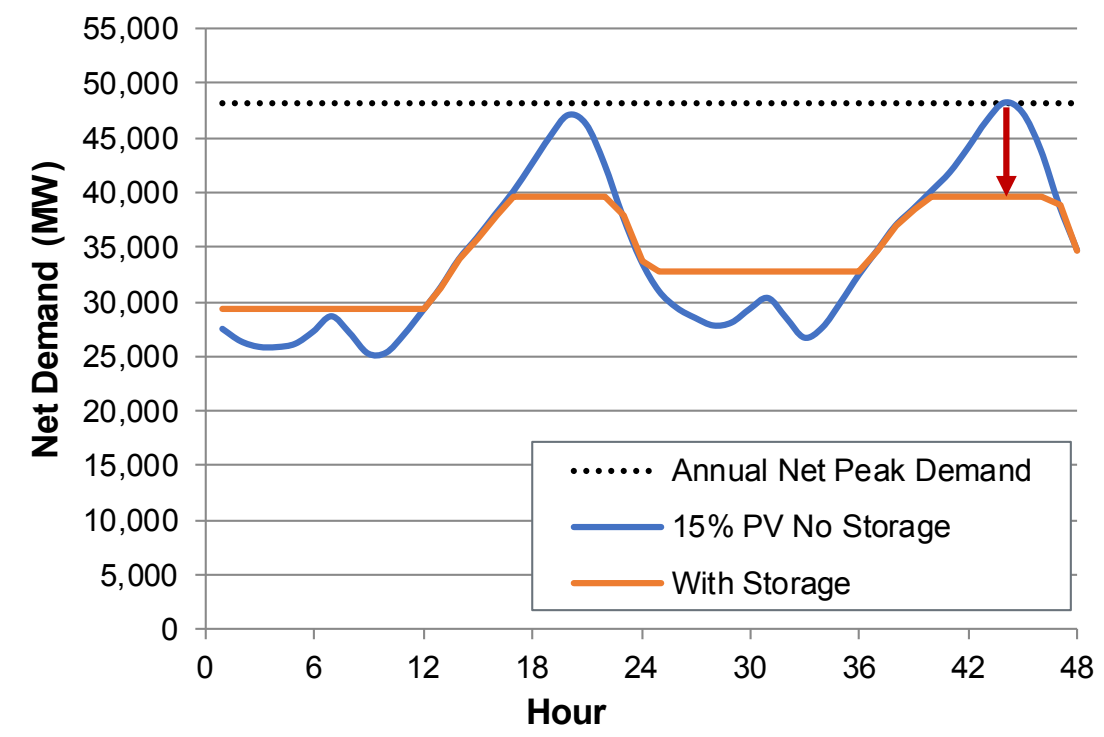

15\% PV. PV generation has reduced net peak demand has been reduced to 48,123 MW. Net demand peak now occurs during period of low solar output and incremental capacity credit of PV is approaching zero. Peak shape has been significantly narrowed. Peak demand reduction with 4 -hr storage at $100 \%$ credit is $8,462 \mathrm{MW}$, or about double the zero PV case.

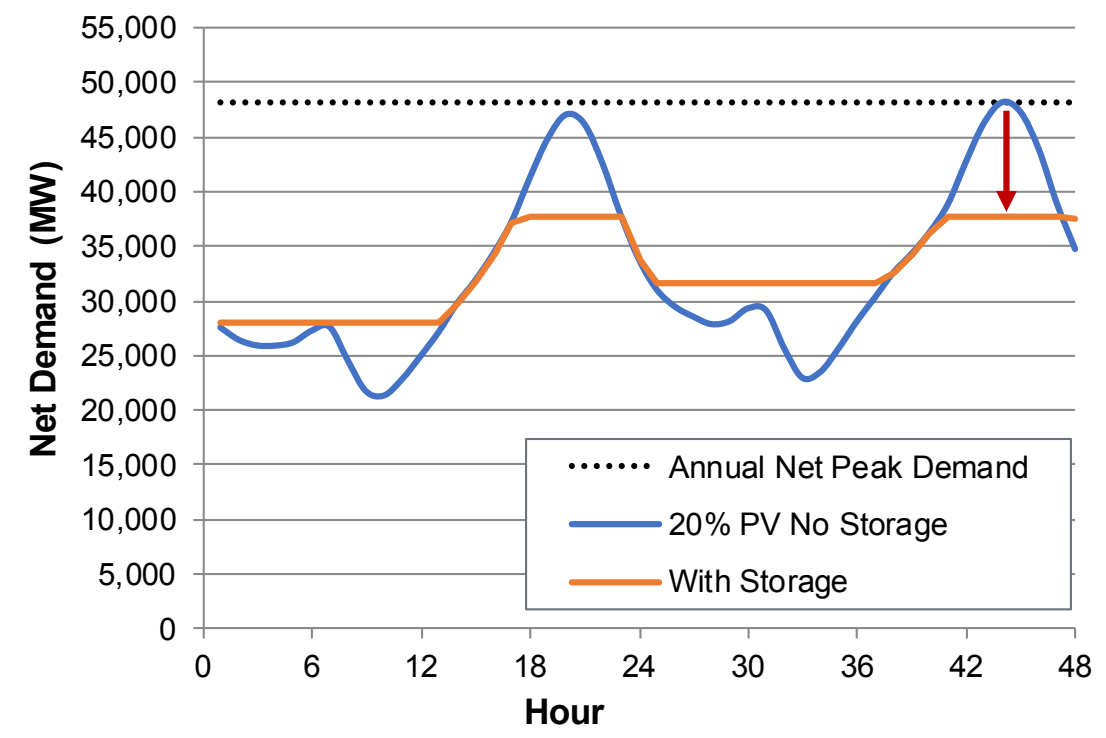

$20 \%$ PV. PV generation has reduced net peak demand to 48,117 MW. Essentially zero incremental capacity credit of PV. The peak continues to narrow. Peak demand reduction with 4-hr storage at $100 \%$ credit is $10,372 \mathrm{MW}$.

Figure A-1. Impact of PV on net demand shape during the 2-day period of annual peak demand using 2011 data 


\section{Appendix B: Comparison to Measured Solar Data}

Our analysis in Section 6 relies on a combination of historical measured load data and simulated PV data (using measured meteorological data from the corresponding year). We use simulated PV data to provide a consistent set of meteorological conditions and PV penetrations across multiple years, particularly during years that may potentially be less favorable for energy storage. However, measured data from within California allows a preliminary evaluation of whether our results are consistent with recent grid conditions.

We acquired measured solar generation data for the years 2012-2017 in the CAISO system. Note that our previous results simulate nearly all of California, whereas the CAISO region serves about $80 \%$ of California. Figure A-2 provides the net load profiles for the peak demand day of each year from 2012 to 2017. These profiles include behind-the-meter (rooftop) PV. Because the estimated behind-the-meter PV penetration in 2017 was over $3 \%,{ }^{24}$ the "no PV" curve is already different than would be expected in a true "no solar" case. Qualitatively, Figure A-2 shows trends similar to those in Figure 10, with a somewhat flatter load in 2014-2015 (when solar penetration was about 6\%-8\%) becoming peakier in 2016 (when solar penetration exceeded $10 \%)$.

${ }^{24}$ Based on 2016 values (CEC 2017b), with projections from GTM and SEIA (2017). 

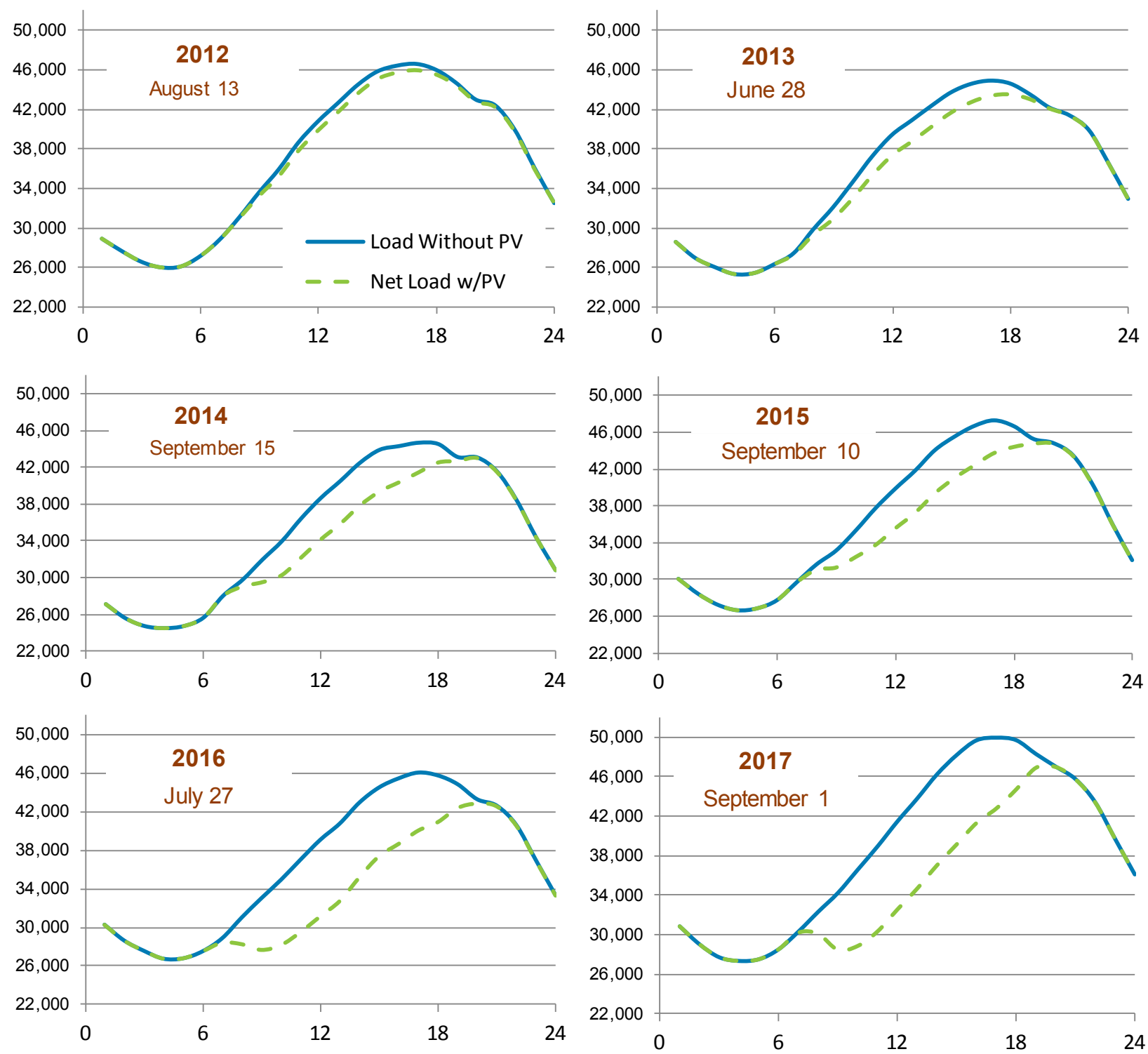

Figure A-2. Net CAISO load during the peak demand day, 2012-2017 (x-axis is hour of day, y-axis is net demand in MW)

This report is available at no cost from the National Renewable Energy Laboratory at www.nrel.gov/publications. 
We simulated the impact of storage on net peak demand using the CAISO data in the same manner as in previous sections. We first scaled the measured PV data for the years 2014-2017 to obtain net load curves for PV penetrations from zero to $30 \%$. Limits to this approach include the lack of spatial diversity that may result at increased levels of PV deployment, in addition to the limited number of years of data. Figure A-3 shows the results, identifying the storage capacity at which the peak demand reduction credit falls below 100\% for 4-hour storage. Because we are comparing two different load data sets, results are normalized to the annual peak demand. Dashed lines show the results using California-wide simulated PV data for the two years where the data sets overlap (2014 and 2015). As with the California-wide data, the PV penetration is an estimate, assuming the rooftop PV penetration in CAISO is the same as it is across all of California. The figure shows that results using simulated PV data are similar to those using measured data. The lines generally track, and the results using 2015 measured PV data show a lower ability of storage to reduce net peak load compared with the 2014 measured data, similar to the results using simulated PV data.

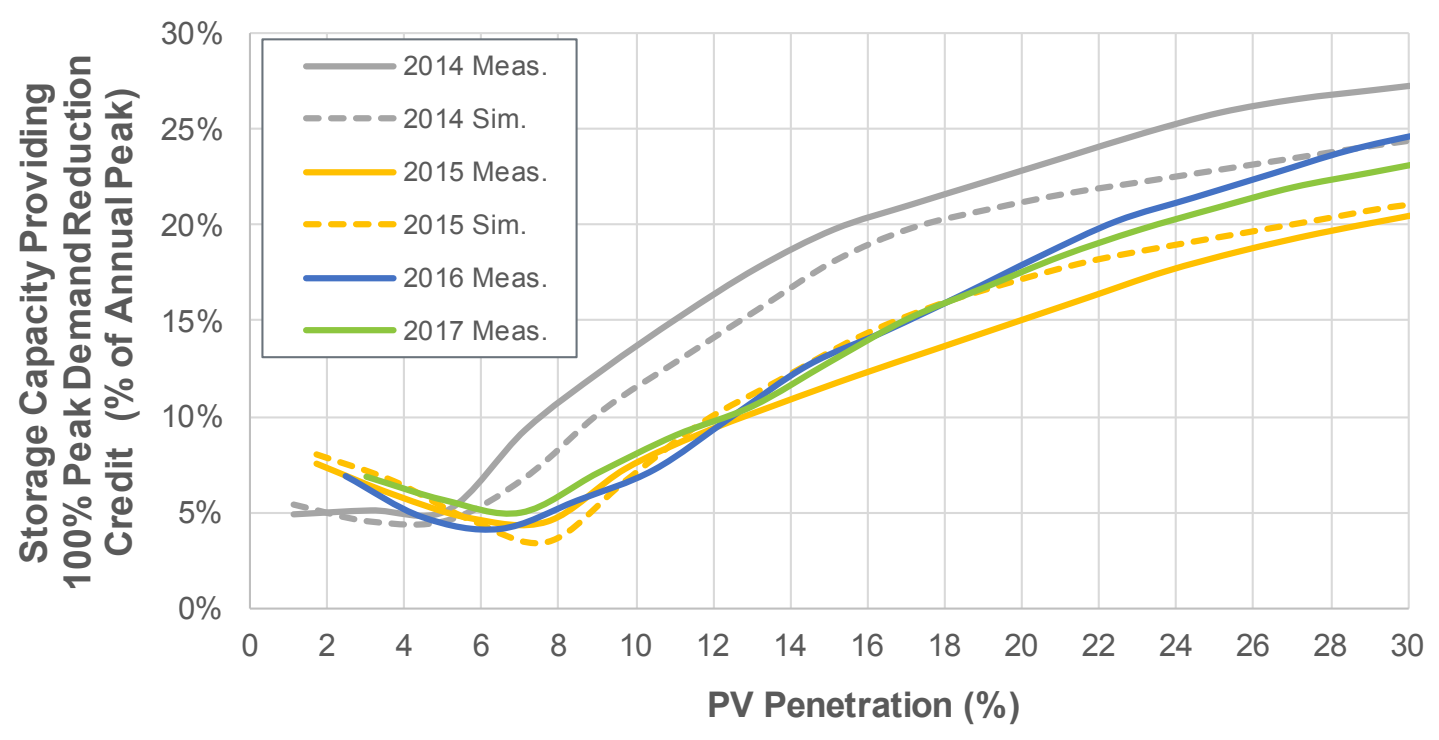

Figure A-3. Threshold values for $100 \%$ peak demand reduction credit for 4-hour energy storage in each year, 2014-2017 (normalized to annual peak) using measured CAISO load and PV data 